\title{
Experimental, Quantum Chemical and Monte Carlo Simulation Studies on the Corrosion Inhibition of Mild Steel by Three New Schiff Base Derivatives
}

\author{
A. Nahlé ${ }^{1, *}$, M. El Azzouzi ${ }^{2}$, A. Aouniti ${ }^{2}$, F. Abrigach ${ }^{2}$, A. Djedouani ${ }^{3,4}$,

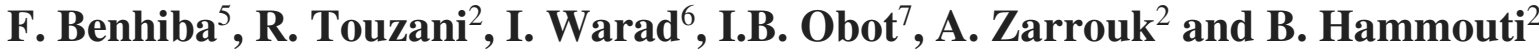 \\ ${ }^{1}$ Department of Chemistry, College of Sciences, University of Sharjah, Sharjah, \\ P.O. Box 27272, United Arab Emirates \\ ${ }^{2}$ LC2AME-URAC 18, Faculty of Science, First Mohammed University, \\ P.O. Box 717, M-60 000 Oujda, Morocco \\ ${ }^{3}$ Laboratory of Physicochemistry Analytic and Crystallochimite of Organometallic and \\ Biomolecular Materials, Constantine \\ ${ }^{4}$ Higher Normal School of Constantine \\ ${ }^{5}$ Laboratory of Separation Procedures, Faculty of Science, University Ibn Tofail, Kenitra, \\ P.O. Box 133, Kenitra, Morocco \\ ${ }^{6}$ Department of Chemistry, AN-Najah National University, P.O. Box 7, Nablus, Palestine. \\ ${ }^{7}$ Centre of Research Excellence in Corrosion, Research Institute, \\ King Fahd University of Petroleum and Minerals, Dhahran 31261, Saudi Arabia
}

"Corresponding author: anahle@ sharjah.ac.ae

Received 29/10/2018; accepted 05/02/2021

https://doi.org/10.4152/pea.2021390501

\begin{abstract}
The corrosion inhibition of newly synthesized Schiff base derivatives, namely (E)-3-(1((2-aminophenyl)imino)ethyl)-4-hydroxy-6-methyl-2H-pyran-2-one (FMO), (E)-3-(1-((3aminophenyl)imino)ethyl)-4-hydroxy-6-methyl-2H-pyran-2-one (FMM), and (E)-3-(1((4-aminophenyl)imino)ethyl)-4-hydroxy-6-methyl-2H-pyran-2-one (FMP) was investigated for mild steel, in a $1.0 \mathrm{M} \mathrm{HCl}$ medium, using weight loss, electrochemical impedance spectroscopy, potentiodynamic polarization and theoretical calculations. FMO, FMM and FMP inhibition effectiveness increased with higher inhibitors concentrations, and decreased with a rise in temperature. Polarization studies showed that FMO, FMM and FMP were of mixed type nature. The results obtained from ACimpedance technique were analyzed to model the corrosion inhibition process through a suitable equivalent circuit model, where a constant phase element (CPE) has been used. FMO, FMM and FMP were found to obey Langmuir adsorption isotherm and KineticThermodynamic Model of El-Awady. Quantum chemical calculations were used to provide molecular based explanations for FMO, FMM and FMP inhibitive effects. Monte Carlo simulation studies and experimental results were in good agreement.
\end{abstract}

Keywords: Mild Steel, corrosion inhibition, Schiff Base derivatives, weight loss, electrochemical techniques and Monte Carlo simulation. 


\section{Introduction}

Mild steel is the most extensively investigated metal for corrosion studies, due to its wide application in various corrosive media. For instance, in oil industries, aqueous acidic media are used for descaling, and acid pickling and treatment. In this case, the exposure of these metals to aqueous acidic solutions causes corrosion. The use of inhibitor substances is one of the most practical approaches to protect the metals from corrosion in acidic environments [1-6]. Organic molecules with polar groups (including $\mathrm{N}, \mathrm{S}$, and $\mathrm{O}$ ), heterocyclic compounds with polar functional groups, and conjugated double bonds can effectively inhibit steel corrosion, due to their chelating action and to the formation of an insoluble physical diffusion barrier on the substrate surface [7-15]. Moreover, the inhibitor substance adsorption onto the steel/corrosive solution interface is affected by the inhibitor molecule chemical structure, the metal nature and charged surface, the distribution of charge over the whole inhibitor molecule, and the type of corrosive medium. If a substitutive polar group $\left(-\mathrm{NH}_{2},-\mathrm{OH},-\mathrm{SH}\right.$, etc.) is added to the $\mathrm{N}$ heterocyclic ring, its electron density will subsequently increase, facilitating the adsorption capacity.

As important N-heterocyclic compounds, Schiff bases are also used as efficient corrosion inhibitors for mild steel in $\mathrm{HCl}$ media, due to the $-\mathrm{C}=\mathrm{N}$ - group presence $[16,17]$. The lone pair of electrons on $\mathrm{N}$ and $\mathrm{O}$ atoms, and the planarity of the molecule inhibitor are important for its adsorption onto the metal surface [18]. Since Schiff's bases are non-toxic and biodegradable, the testing of their corrosion protective properties is significant, in the context of the current priority to synthesize inhibitor molecules with low environmental impact.

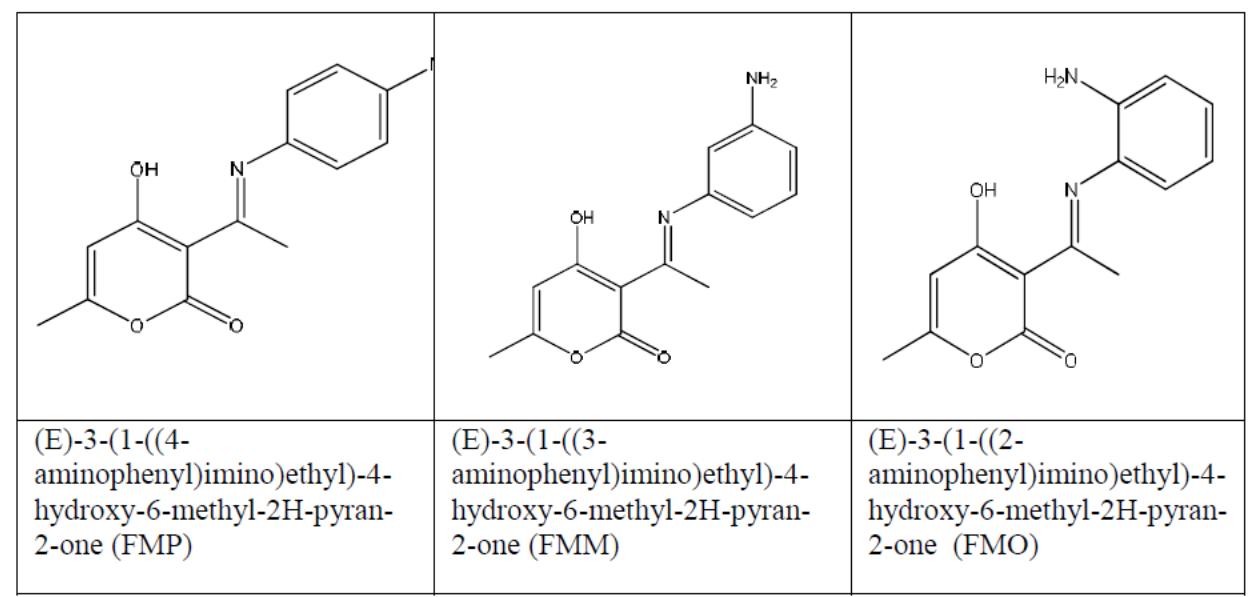

Figure 1. Chemical structures of the studied Schiff base derivatives.

Several authors have demonstrated that, not only the p electron of the Schiff bases enters unoccupied orbitals of transition metals, but also that the $\pi^{*}$ orbital can accept the electrons of transition metal d-orbitals, to form feedback bonds [19], thus enabling the existence of a metal-inhibitor bond. In addition, Schiff bases have recently been reported as effective corrosion inhibitor substances for various metals, such as steel, aluminum and copper, in acidic media. The greatest advantages of Schiff bases are [20,21]: (a) they can be conveniently synthesized 
from inexpensive raw materials; (b) they contain an electron cloud on the aromatic ring or electronegative atoms, such as nitrogen and sulfur, in relatively long chain compounds; (c) and they are harmless to the environment, which encouraged us to test this type of inhibitor.

In the present work, FMO, FMM and FMP corrosion inhibitive behavior, mechanism and effectiveness, on mild steel in hydrochloric acid solutions, was examined and studied by DFT (Density Functional Theory) and Monte Carlo simulation. The structures of these tested inhibitors are shown in Fig. 1.

\section{Experimental details \\ Materials}

The steel used in this study was mild steel, with a chemical composition (in wt \%) of $0.09 \% \mathrm{P}, 0.01 \% \mathrm{Al}, 0.38 \% \mathrm{Si}, 0.05 \% \mathrm{Mn}, 0.21 \% \mathrm{C}, 0.05 \% \mathrm{~S}$, and the remainder iron $(\mathrm{Fe})$. The specimens and solutions were prepared as reported earlier [22].

\section{Solutions}

The $1.0 \mathrm{M} \mathrm{HCl}$ aggressive solutions were prepared by dilution of analytical grade $37 \% \mathrm{HCl}$ with distilled water. The concentration of (E)-3-(1-((2aminophenyl)imino)ethyl)-4-hydroxy-6-methyl-2H-pyran-2-one (FMO), (E)-3-(1((3-aminophenyl)imino)ethyl)-4-hydroxy-6-methyl-2H-pyran-2-one (FMM) and (E)-3-(1-((4-aminophenyl)imino)ethyl)-4-hydroxy-6-methyl-2H-pyran-2-one (FMP) ranged from $1.0 \times 10^{-5} \mathrm{M}$ to $1.0 \times 10^{-3} \mathrm{M}$.

\section{Corrosion tests}

\section{Weight loss measurements}

Gravimetric experiments were performed according to the "ASTM G 31-72" standard method [23]. Weight loss experiments were carried out as described in the literature [22]. All experiments were performed in triplicate, average values were reported, and good reproducibility was obtained. The corrosion rate $(v)$ and the inhibition efficiency $(\eta)$ were calculated using the following equations [24]:

$$
\begin{aligned}
& v=\frac{W}{s \cdot t} \\
& \eta(\%)=\frac{v_{0}-v}{v_{0}} \times 100
\end{aligned}
$$

where $\mathrm{W}$ is the three-experiment mild steel average weight loss, $\mathrm{S}$ is the total surface area of the specimen, $t$ is the immersion time and $v_{0}$ and $v$ are the corrosion rate values, without and with FMO, FMM and FMP addition, respectively. The fractional surface coverage, $\theta$, can be easily determined from weight loss measurements by the ratio $\eta(\%) / 100$, if one assumes that $\eta(\%)$ values do no differ substantially from $\theta$.

\section{Electrochemical measurements}

The electrochemical measurements were carried out using a Volta lab (TacusselRadiometer PGZ 100) potentiostat, and controlled with Tacussel corrosion analysis software model (Voltamaster 4), under a static condition. The electrochemical experiments were conducted as reported earlier [22]. From the 
obtained polarization curves, the corrosion current $\left(\mathrm{I}_{\text {corr }}\right)$ was calculated by curve fitting, using the following equation:

$$
I=I_{\operatorname{corr}}\left[\exp \left(\frac{2.3 \Delta E}{\beta_{\pi}}\right)-\exp \left(\frac{2.3 \Delta E}{\beta_{\Omega}}\right)\right]
$$

where $\beta_{\mathrm{a}}$ and $\beta_{\mathrm{c}}$ are the anodic and cathodic Tafel slopes, respectively, and $\Delta \mathrm{E}$ is $\mathrm{E}$ - Ecorr.

The inhibition efficiency was evaluated from the measured $I_{\text {corr }}$ values using the following relationship:

$$
\eta(\%)=\frac{s_{\text {sorr }}-t_{\text {corr }(i)}}{I_{\text {cort }}} \times 100
$$

where $\mathrm{I}_{\text {corr }}$ and $\mathrm{I}_{\text {corr(i) }}$ are the corrosion current densities for mild steel electrode, in the uninhibited and inhibited solutions, respectively.

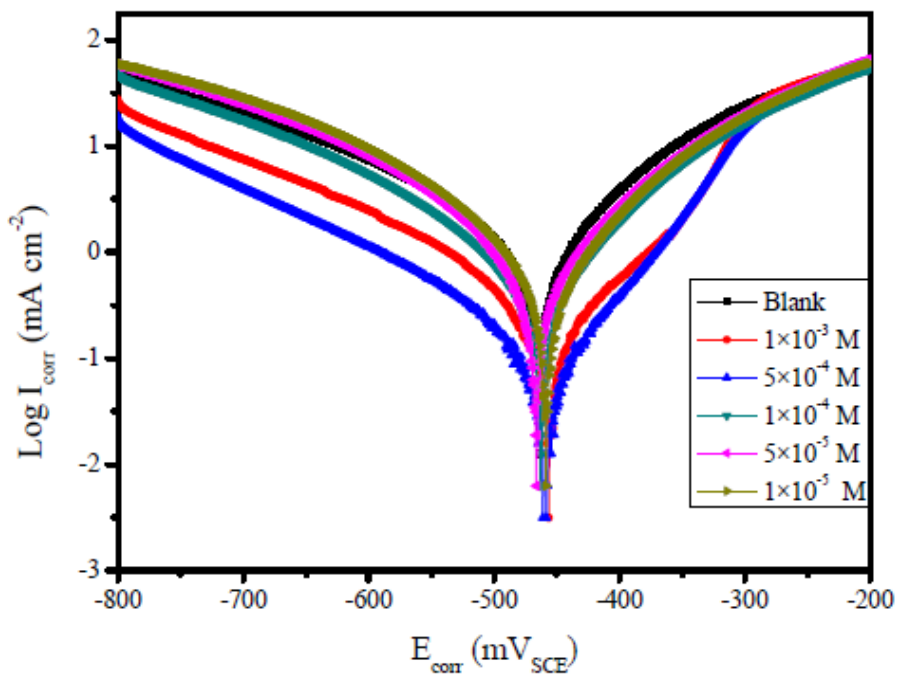

Figure 2. Polarization curves of mild steel, in $1.0 \mathrm{M} \mathrm{HCl}$, with and without different FMM concentrations, at $308 \mathrm{~K}$.

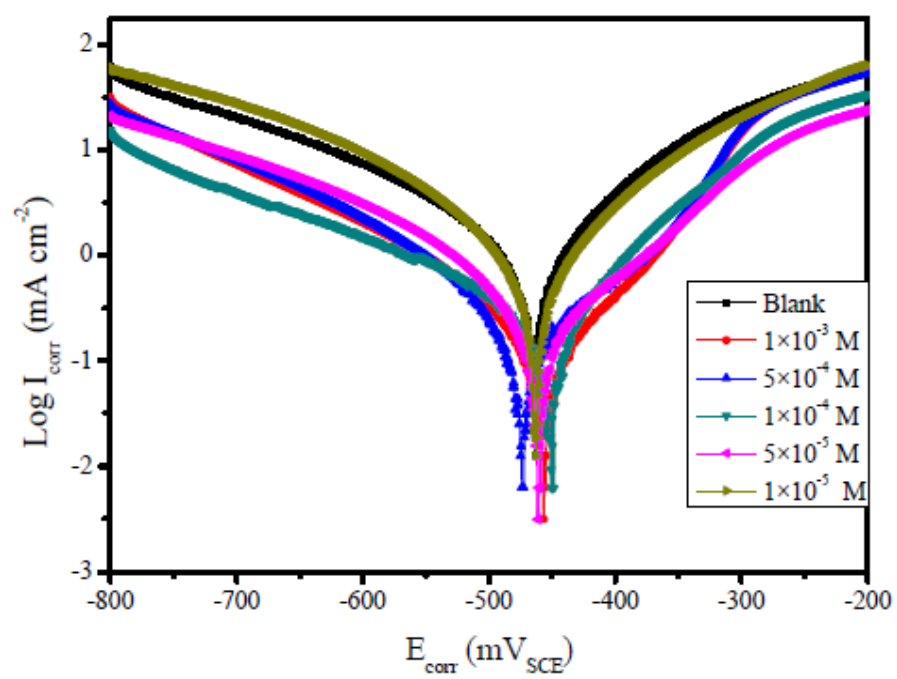

Figure 3. Polarization curves of mild steel, in $1.0 \mathrm{M} \mathrm{HCl}$, with and without different FMO concentrations, at $308 \mathrm{~K}$. 


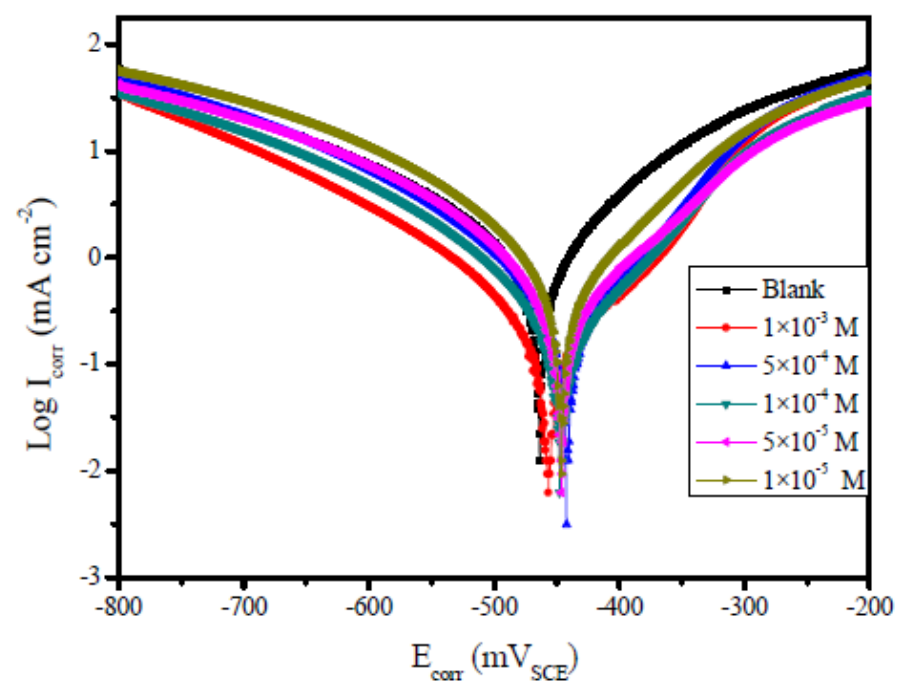

Figure 4. Polarization curves of mild steel, in $1.0 \mathrm{M} \mathrm{HCl}$, with and without different FMP concentrations, at $308 \mathrm{~K}$.

\section{Results and discussion}

\section{Potentiodynamic polarization curves}

Figs. 2 to 4 show the typical Tafel curves obtained for mild steel, in $1.0 \mathrm{M} \mathrm{HCl}$ with and without FMO, FMM and FMP compounds.

The values of potentiodynamic kinetics parameters, i.e. corrosion potential $\left(\mathrm{E}_{\mathrm{corr}}\right)$, corrosion current density $\left(\mathrm{I}_{\mathrm{corr}}\right)$, anodic Tafel slopes $\left(\beta_{\mathrm{a}}\right)$, cathodic Tafel slopes $\left(\beta_{\mathrm{c}}\right)$ and inhibition efficiency $(\eta(\%))$ values were determined from the polarization curve, being presented in Table 1 .

Table 1. Electrochemical parameters for mild steel, in a $1.0 \mathrm{M} \mathrm{HCl}$ solution, without and with different concentrations of Schiff base derivatives, at $308 \mathrm{~K}$.

\begin{tabular}{|c|c|c|c|c|c|c|}
\hline Medium & $\begin{array}{l}\text { Conc. } \\
\text { (M) }\end{array}$ & $\begin{array}{c}\text {-Ecorr } \\
\text { (mV vs. SCE) }\end{array}$ & $\begin{array}{c}-\beta c \\
(m V \text { dec-1) }\end{array}$ & $\begin{array}{c}\boldsymbol{\beta a} \\
(\mathrm{mV} \text { dec-1) }\end{array}$ & $\begin{array}{c}\text { Icorr } \\
(\mu \mathrm{A} \text { cm-2) }\end{array}$ & $\begin{array}{c}\eta \\
(\%)\end{array}$ \\
\hline Blank & 1.0 & 460.3 & 267.4 & 219.1 & 2979.6 & - \\
\hline \multirow{5}{*}{ FMM } & $1.0 \times 10^{-3}$ & 456.9 & 159.6 & 94.2 & 141.9 & 95.1 \\
\hline & $5.0 \times 10^{-4}$ & 459.1 & 181.0 & 85.0 & 187.2 & 93.5 \\
\hline & $1.0 \times 10^{-4}$ & 463.5 & 172.2 & 126.2 & 864.8 & 70.1 \\
\hline & $5.0 \times 10^{-5}$ & 467.2 & 183.5 & 147.6 & 1504.2 & 45.0 \\
\hline & $1.0 \times 10^{-5}$ & 459.2 & 195.5 & 159.6 & 1868.9 & 35.4 \\
\hline \multirow{5}{*}{ FMO } & $1.0 \times 10^{-3}$ & 457.5 & 184.0 & 95.7 & 350.9 & 87.9 \\
\hline & $5.0 \times 10^{-4}$ & 474.0 & 175.7 & 87.6 & 446.0 & 84.6 \\
\hline & $1.0 \times 10^{-4}$ & 464.8 & 164.2 & 125.8 & 567.1 & 80.4 \\
\hline & $5 \times 10^{-5}$ & 461.6 & 216.3 & 156.2 & 723.4 & 75.0 \\
\hline & $1.0 \times 10^{-5}$ & 464.1 & 207.0 & 169.8 & 2195.6 & 24.1 \\
\hline \multirow{5}{*}{ FMP } & $1.0 \times 10^{-3}$ & 457.3 & 166.1 & 107.9 & 418.5 & 85.5 \\
\hline & $5.0 \times 10^{-4}$ & 442.6 & 160.9 & 109.1 & 696.3 & 75.9 \\
\hline & $1.0 \times 10^{-4}$ & 447.0 & 186.4 & 131.2 & 735.1 & 74.6 \\
\hline & $5.0 \times 10^{-5}$ & 446.7 & 211.1 & 1706.0 & 1362.3 & 52.9 \\
\hline & $1.0 \times 10^{-5}$ & 447.0 & 220.5 & 175.4 & 2304.2 & 20.3 \\
\hline
\end{tabular}

In FMO, FMM and FMP inhibitors presence, the curves shift towards a lower current density region, compared to the blank acid medium. This suggests that the studied FMO, FMM and FMP molecules reduce the corrosion current and, 
therefore, decrease the corrosion rate. The polarization curves also exhibit some shifts in potential towards more anodic or cathodic regions, relatively to the acidic blank solution. The direction of the shift is not uniform, as it varies with FMO, FMM and FMP concentrations. This suggests that FMO, FMM and FMP compounds affect both the anodic and cathodic corrosion reactions. The parallel cathodic polarization curves, shown in Figs. 2 to 4, indicate that FMO, FMM and FMP molecules do not change the mechanism of hydrogen reduction, and that the hydrogen evolution is activation-controlled.

The Tafel slopes, $\beta_{\mathrm{a}}$ and $\beta_{\mathrm{c}}$ values show a change with the added FMO, FMM and FMP concentrations, being generally lower than those of the blank. Obviously, a greater decrease in $\mathrm{I}_{\text {corr }}$ values was observed at high FMO, FMM and FMP concentrations. In general, an inhibitor can be classified as of the anodic or cathodic type, if the shift in $\mathrm{E}_{\text {corr }}$ is higher than $85 \mathrm{mV}$, with respect to the blank $E_{\text {corr, }}$ and as a mixed type inhibitor, if the shift in the $E_{\text {corr }}$ is lower than $85 \mathrm{mV}[25$, $26]$. In our present investigation, maximum displacement in the $E_{\text {corr }}$ values was $6.9 \mathrm{mV}$ for FMM, $13.7 \mathrm{mV}$ for FMO and $17.7 \mathrm{mV}$ for FMP.

Table 1 shows a decrease in the corrosion rate, in FMO, FMM and FMP presence. This effect is hugely marked at higher FMO, FMM and FMP concentrations. The inhibitive action is more explicit using $\eta(\%)$ data, increasing with higher inhibitor concentrations, reaching 85.5 \% for FMP, 87.9 \% for FMO and 95.1\% for FMM, at $1.0 \times 10^{-3} \mathrm{M}$. FMO, FMM and FMP inhibited mild steel corrosion in $1.0 \mathrm{M} \mathrm{HCl}$, but the FMM inhibitor was found to exhibit the best inhibition action. The protective properties of such compounds are probably due to the interaction between $\pi$-electrons of the benzene and pyran rings, and the positively charged mild steel surface. The oxygen and nitrogen atoms are the adsorption centers for their interaction with the metal surface [27].

\section{Electrochemical impedance spectroscopy (EIS)}

The effect of FMO, FMM, and FMP on mild steel corrosion inhibition, in $1.0 \mathrm{M}$ $\mathrm{HCl}$, was also investigated by EIS method. The Nyquist plots obtained for mild steel in $1.0 \mathrm{M} \mathrm{HCl}$, in the absence and presence of different FMO, FMM and FMP concentrations, are shown in Figs. 5 to 7.

It is obvious that the EIS spectra of FMO, FMM and FMP with and without solutions show similar characteristics, suggesting that the mild steel corrosion mechanism is similar in both cases. The impedance spectra, at different concentrations of the investigated Schiff base derivatives, showed a single capacitive loop, which suggests that FMO, FMM and FMP adsorption took place through simple surface coverage, and that the studied compounds behaved as primary interface inhibitors [28]. It is also evident, from Figs. 5 to 7, that the diameter of the Nyquist plots increases with higher FMO, FMM and FMP concentrations, which is attributed to the formation of a protective film on the mild steel surface, leading to a successful retardation of the corrosion process [29]. 


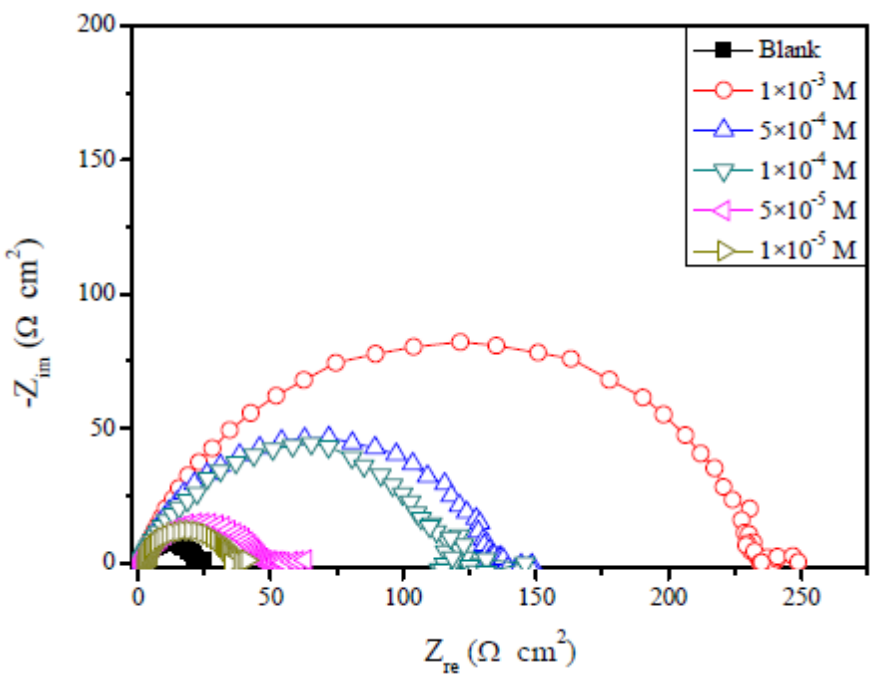

Figure 5. Nyquist diagrams for mild steel, in $1.0 \mathrm{M} \mathrm{HCl}$, at different FMM concentrations, at $308 \mathrm{~K}$.

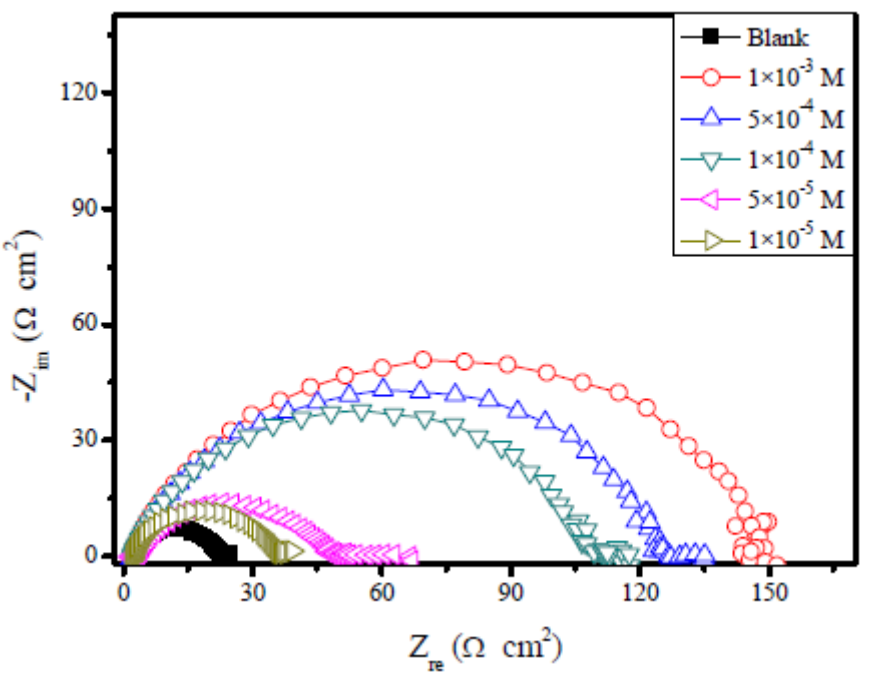

Figure 6. Nyquist diagrams for mild steel, in $1.0 \mathrm{M} \mathrm{HCl}$, at different FMO concentrations, at $308 \mathrm{~K}$.

For a metallic system corroding in an acidic solution (in our case, $1.0 \mathrm{M} \mathrm{HCl}$ ), the replacement of capacitance by CPE gives a better approximation [30]. CPE is defined in impedance representation, as follows:

$$
Z_{C P E}=Q^{-1}(i \omega)^{-n}
$$

where $\mathrm{Q}$ is the CPE constant, $\omega$ is the angular frequency $\left(\mathrm{rad} \mathrm{s}^{-1}\right), \mathrm{i}^{2}=-1$ is the imaginary number and $\mathrm{n}$ is a CPE exponent that can be utilized as a gauge of the surface heterogeneity or roughness [31].

Depending on $n$ value, CPE can represent resistance $(n=0, A=R)$, capacitance ( $n$ $=1, \mathrm{~A}=\mathrm{C})$, inductance $(\mathrm{n}=-1, \mathrm{~A}=\mathrm{L})$ or Warburg impedance $(\mathrm{n}=0.5, \mathrm{~A}=\mathrm{W})$.

The transfer function is, thus, represented by an equivalent circuit that has been previously used [31, 32] with only one time constant (Fig. 8). Parallel to the double-layer capacitance (simulated by a $\mathrm{CPE}$ ) is the charge transfer resistance $\left(\mathrm{R}_{\mathrm{ct}}\right)$; and $\mathrm{R}_{\mathrm{s}}$ is the electrolyte (in our case, $1.0 \mathrm{M} \mathrm{HCl}$ ) resistance. 


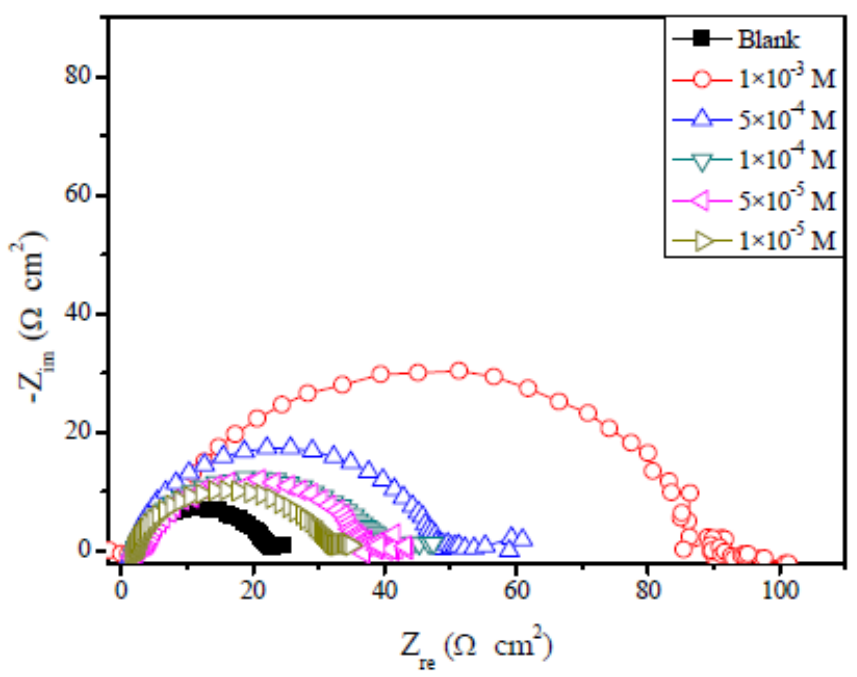

Figure 7. Nyquist diagrams for mild steel, in $1.0 \mathrm{M} \mathrm{HCl}$, at different FMP concentrations, at $308 \mathrm{~K}$.

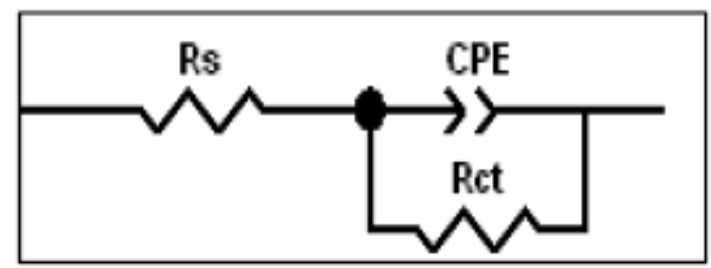

Figure 8. Electrical equivalent circuit used for modelling the metal/solution interface.

The electrochemical parameters, obtained from fitting the recorded EIS data using the equivalent circuit of Fig. 8, are presented in Table 2. This table shows the calculated "double layer capacitance" values, $C_{\mathrm{dl}}$, extracted from the CPE parameters, according to [33]:

$$
C_{d l}=\left(Q \cdot R_{c t}^{1-n}\right)^{1 / n}
$$

where $\mathrm{C}_{\mathrm{dl}}$ is the double layer capacitance, $\mathrm{Q}$ is the CPE constant, $\mathrm{R}_{\mathrm{ct}}$ is the charge transfer resistance and $\mathrm{n}$ is a CPE exponent.

The relaxation time constants were calculated according to the dielectric theory:

$$
\tau=\frac{1}{2 \pi f_{\max }}
$$

where $f_{\max }$ is the frequency at which the maximum in the $-\varphi$ curve (phase shift) vs. $\log f$ appears. The relaxation time $(\tau)$ of a surface state is the time required for the return of the charge distribution to equilibrium, after an electrical disturbance; and, in the case, when no distributed element is enclosed to replace the double layer capacitance, it is defined [34] as:

$$
\tau=C_{d V} R_{\text {ot }}
$$

where $\tau$ is the relaxation time, $C_{d l}$ is the double layer capacitance and $R_{c t}$ is the charge transfer resistance. 
From Table 2, the lower values of the constant phase element (CPE), Q, in FMO, FMM and FMP presence, compared to the blank, indicate that the inhibitor substances are adsorbed onto the mild steel surface, forming a protective layer.

It is apparent that the mild steel charge transfer resistance $\left(R_{c t}\right)$ value, in a 1.0 $\mathrm{M} \mathrm{HCl}$ solution, increases significantly after FMO, FMM and FMP addition. FMO, FMM and FMP addition to the corrosive solution decreases the double layer capacitance. The double layer between the charged metal surface and the solution is considered as an electrical capacitor. The decrease in this capacity could be attributed to FMO, FMM and FMP adsorption, which forms protective adsorption layers onto the metal surface [35]. The time constant $(\tau)$ calculated values, obtained in FMO, FMM and FMP presence, were found to be higher than those of the uninhibited solution.

Table 2. Impedance parameters and inhibition efficiency values for mild steel, in $1.0 \mathrm{M}$ $\mathrm{HCl}$, at different concentrations of Schiff base derivatives, at $308 \mathrm{~K}$.

\begin{tabular}{|c|c|c|c|c|c|c|c|c|}
\hline Medium & $\begin{array}{l}\text { Conc. } \\
\text { (M) }\end{array}$ & $\begin{array}{c}\boldsymbol{R}_{s} \\
\left(\boldsymbol{\Omega} \mathrm{cm}^{2}\right)\end{array}$ & $\begin{array}{c}\boldsymbol{R}_{c t} \\
\left(\boldsymbol{\Omega} \mathbf{c m}^{2}\right)\end{array}$ & $\underset{\left(\mu \Omega^{-1} \mathbf{s}^{\mathbf{n}} \mathbf{c m}^{-2}\right)}{Q}$ & $n$ & $\begin{array}{c}C_{d l} \\
\left(\mu \mathrm{F} \mathbf{c m}^{-2}\right)\end{array}$ & $\begin{array}{c}\tau \\
(\mathbf{m s})\end{array}$ & $\begin{array}{c}\eta \\
(\%)\end{array}$ \\
\hline Blank & 1 & 2.15 & 20.4 & 514.27 & 0.795 & 158.86 & 3.2450 & - \\
\hline \multirow{5}{*}{ FMP } & $1.0 \times 10^{-3}$ & 3.15 & 87.4 & 163.67 & 0.907 & 105.87 & 9.2530 & 76.6 \\
\hline & $5.0 \times 10^{-4}$ & 1.83 & 45.6 & 212.20 & 0.889 & 118.92 & 5.4227 & 55.3 \\
\hline & $1.0 \times 10^{-4}$ & 2.20 & 37.3 & 265.55 & 0.877 & 139.22 & 5.1929 & 45.3 \\
\hline & $5.0 \times 10^{-5}$ & 3.50 & 34.4 & 305.96 & 0.865 & 150.31 & 5.1707 & 40.7 \\
\hline & $1.0 \times 10^{-5}$ & 1.88 & 29.8 & 363.32 & 0.843 & 156.40 & 4.6607 & 31.5 \\
\hline \multirow{5}{*}{ FMO } & $1.0 \times 10^{-3}$ & 1.87 & 146.2 & 194.16 & 0.850 & 103.56 & 15.1405 & 86.0 \\
\hline & $5.0 \times 10^{-4}$ & 1.98 & 123.0 & 226.72 & 0.845 & 117.58 & 14.4623 & 83.4 \\
\hline & $1.0 \times 10^{-4}$ & 2.20 & 104.8 & 266.20 & 0.842 & 135.99 & 14.2517 & 80.5 \\
\hline & $5.0 \times 10^{-5}$ & 6.35 & 42.8 & 345.67 & 0.830 & 145.83 & 6.2415 & 52.3 \\
\hline & $1.0 \times 10^{-5}$ & 2.09 & 33.6 & 402.97 & 0.819 & 155.72 & 5.2322 & 39.3 \\
\hline \multirow{5}{*}{ FMM } & $1.0 \times 10^{-3}$ & 1.98 & 225.6 & 201.29 & 0.810 & 97.46 & 21.9870 & 91.0 \\
\hline & $5.0 \times 10^{-4}$ & 1.87 & 129.8 & 252.78 & 0.808 & 112.23 & 14.5674 & 84.3 \\
\hline & $1.0 \times 10^{-4}$ & 1.90 & 119.7 & 268.36 & 0.802 & 114.83 & 13.7451 & 83.0 \\
\hline & $5.0 \times 10^{-5}$ & 2.58 & 43.7 & 359.93 & 0.801 & 128.29 & 5.6063 & 53.3 \\
\hline & $1.0 \times 10^{-5}$ & 2.50 & 33.9 & 432.13 & 0.797 & 147.38 & 4.9962 & 39.8 \\
\hline
\end{tabular}

The inhibitory efficiency, $\eta(\%)$, is calculated by $\mathrm{R}_{\mathrm{ct}}$, using equation (9):

$$
\eta \%=\frac{R_{c t}^{i}-R_{c t}^{0}}{R_{c t}^{i}} \times 100
$$

where $\eta(\%)$ is the inhibition efficiency, $R_{c t}^{\circ}$ is the charge-transfer resistance value, without and with inhibitor, and $R_{c t}^{i}$ is the charge-transfer resistance value with inhibitor. It is obvious from the results that the inhibition efficacy, calculated from electrochemical impedance, is in agreement with the effectiveness calculated from polarization measurements.

\section{Weight loss measurements}

\section{Effect of inhibitor concentration}

The $\eta(\%)$ and the corrosion rate $(v)$ values, obtained from weight loss method, at various FMP, FMO and FMM concentrations, are summarized in Table 3. It has 
been found that the FMP, FMO and FMM compounds inhibit mild steel corrosion, at all the studied concentrations. The lone pair of electrons on the nitrogen and oxygen atoms, and also the presence of a higher electron density in the inhibitor molecules, will coordinate with the metal active sites, which causes a stronger interaction with the metal surface. The presence of $\pi$ electrons on nitrogen and oxygen atoms enhances the inhibitor substances adsorption onto the metal surface, and, hence, inhibits the corrosion process [36].

Table 3. Weight loss data for mild steel, in $1.0 \mathrm{M} \mathrm{HCl}$, without and with different concentrations of Schiff base derivatives, at $308 \mathrm{~K}$.

\begin{tabular}{|c|c|c|c|c|}
\hline Medium & $\begin{array}{l}\text { Conc. } \\
\text { (M) }\end{array}$ & $\begin{array}{c}v \\
\left(\mathrm{mg} \mathrm{cm}^{-2} \mathbf{h}^{-1}\right)\end{array}$ & $\begin{array}{c}\eta \\
(\%)\end{array}$ & $\theta$ \\
\hline Blank & 1.0 & 0.744 & - & - \\
\hline \multirow{5}{*}{ FMP } & $1.0 \times 10^{-5}$ & 0.708 & 04.8 & 0.048 \\
\hline & $5.0 \times 10^{-5}$ & 0.617 & 17.1 & 0.171 \\
\hline & $1.0 \times 10^{-4}$ & 0.565 & 24.1 & 0.241 \\
\hline & $5.0 \times 10^{-4}$ & 0.334 & 55.1 & 0.551 \\
\hline & $1.0 \times 10^{-3}$ & 0.275 & 63.0 & 0.630 \\
\hline \multirow{5}{*}{ FMO } & $1.0 \times 10^{-5}$ & 0.684 & 08.1 & 0.081 \\
\hline & $5.0 \times 10^{-5}$ & 0.580 & 22.0 & 0.220 \\
\hline & $1.0 \times 10^{-4}$ & 0.483 & 35.1 & 0.351 \\
\hline & $5.0 \times 10^{-4}$ & 0.267 & 64.1 & 0.641 \\
\hline & $1.0 \times 10^{-3}$ & 0.163 & 78.1 & 0.781 \\
\hline \multirow{5}{*}{ FMM } & $1.0 \times 10^{-5}$ & 0.647 & 13.0 & 0.130 \\
\hline & $5.0 \times 10^{-5}$ & 0.528 & 29.0 & 0.290 \\
\hline & $1.0 \times 10^{-4}$ & 0.252 & 66.1 & 0.661 \\
\hline & $5.0 \times 10^{-4}$ & 0.178 & 76.1 & 0.761 \\
\hline & $1.0 \times 10^{-3}$ & 0.096 & 87.1 & 0.871 \\
\hline
\end{tabular}

Table 3 shows that the corrosion rates, in FMP, FMO and FMM presence, were $0.275 \mathrm{mg} \mathrm{cm}^{-2} \mathrm{~h}^{-1}, 0.163 \mathrm{mg} \mathrm{cm}^{-2} \mathrm{~h}^{-1}$ and $0.096 \mathrm{mg} \mathrm{cm}^{-2} \mathrm{~h}^{-1}$, respectively, at the concentration of $1.0 \times 10^{-3} \mathrm{M}$, and that they decreased significantly, compared to the blank solution $\left(0.744 \mathrm{mg} \mathrm{cm}^{-2} \mathrm{~h}^{-1}\right)$. This significant decrease in the corrosion rate suggests that the FMP, FMO and FMM molecules are highly effective corrosion inhibitors, even at higher concentrations of the acidic solution.

\section{Adsorption considerations}

A direct relationship between the percentage inhibition, $\eta(\%)$ and the degree of surface coverage $(\theta)[\eta(\%)=100 \times \theta]$ can be assumed for the different FMP, FMO and FMM concentrations. The degree of surface coverage $(\theta)$, for the different FMP, FMO and FMM concentrations, has been evaluated from the weight loss measurements, in $1.0 \mathrm{M} \mathrm{HCl}$, at $308 \mathrm{~K}$. The data were graphically examined by fitting to several adsorption isotherms, including Freundlich, Temkin, FloryHuggins, Bockris-Swinkles, Langmuir and Frumkin isotherms. The correlation coefficient $\left(\mathrm{R}^{2}\right)$ was utilized to determine the best fit isotherm which was obtained for Langmuir. According to this isotherm, $\theta$ is related to FMP, FMO and FMM concentrations, using the following equation (10) [37]: 


$$
\frac{b c}{\theta}=\frac{1}{K_{a d s}}+C
$$

where $\theta$ is the surface coverage, $C$ is the concentration and $K_{a d s}$ is the equilibrium constant of the adsorption process expressed in $\mathrm{L} \mathrm{mol}^{-1}$. $\mathrm{K}_{\mathrm{ads}}$ is associated to the standard Gibbs free energy of adsorption $\left(\Delta \mathrm{G}_{\mathrm{ads}}^{\circ}\right)$ and is calculated by equation (11) [38]. The data were plotted in Fig. 9. The intercept of the lines in Fig. 9 yielded $\mathrm{K}_{\mathrm{ads}}$ in $\mathrm{L} \mathrm{mol}^{-1}$, and the corresponding standard Gibbs free energy of adsorption, in $\left(\mathrm{kJ} \mathrm{mol}^{-1}\right)$, was calculated using equation (11) [38]:

$$
K_{\text {ads }}=\frac{1}{c_{\text {solvent }}} \exp \left(\frac{-\Delta G_{R d s}^{0}}{R T}\right)
$$

where $\mathrm{K}_{\mathrm{ads}}$ is the equilibrium constant of adsorption process, $\mathrm{C}_{\text {solvent }}$ is the molar concentration of water $\left(\mathrm{C}_{\mathrm{H}_{2} \mathrm{O}}=55.5 \mathrm{~mol} \mathrm{dm}^{-3}\right), \Delta \mathrm{G}_{\mathrm{ads}}^{\circ}$ is Gibbs free energy of adsorption, $\mathrm{R}$ is the gas constant and $\mathrm{T}$ is the temperature expressed in $\mathrm{K}$.

Using equation 11, the various adsorption parameters were calculated from the studied isotherm, including the standard Gibbs free energy of adsorption of FMP, FMO and FMM on the mild steel surface, at $308 \mathrm{~K}$, and are presented in Table 4.

Fig. 9 shows the plot of $\mathrm{C} / \theta$ versus $\mathrm{C}$, and linear plots were obtained for FMP, FMO and FMM, indicating that these inhibitors adsorption followed Langmuir isotherm. The various adsorption parameters obtained from this isotherm are listed in Table 4 . The correlation coefficients were very good, and $\mathrm{K}_{\mathrm{ads}}$ values increased with higher inhibitors concentrations, showing that FMP, FMO and FMM molecules were adsorbed onto the mild steel surface.

Although the plots are linear, as depicted by $\mathrm{R}^{2}$ values $(0.99)$, the slopes pervert from the unity value, as expected from the ideal Langmuir adsorption equation. This remoteness may be explained on the basis of the interaction among adsorbed species on the metal surface. It has been posited in the derivation of Langmuir isotherm equation that adsorbed molecules do not interact with each another. However, this is not true in the case of large organic molecules with polar atoms or groups which can be adsorbed on the cathodic and anodic sites of the metal surface. Such adsorbed species interact by mutual repulsion or attraction. It is also possible that the FMP, FMO and FMM are adsorbed on the anodic and cathodic sites, which results in a deviation from the unit gradient. Similar observations have been mentioned in the literature [39, 40].

However, it is observed that the slope (Table 4) has remarkably deviated from the unity required by an ideal Langmuir isotherm model. Langmuir equation has been derived under the assumption that adsorbed species do not interact with each other [41]. This assumption is not true, as authors [42-44] have demonstrated that adsorbed inhibitor species are capable of interacting with each other on the metal surface. For this reason, $\theta$ values were fitted into El-Awady [43] kinetic/thermodynamic adsorption model, which is a modification of the Langmuir isotherm, and takes into consideration the omitted interaction parameter by Langmuir isotherm. Equation (12) [45] gives the description of the El-Awady kinetic/thermodynamic adsorption model [43].

$$
\operatorname{Ln}\left(\frac{\theta}{1-\theta}\right)=\operatorname{Ln} K^{\prime}+y \operatorname{Ln} C
$$


where $\mathrm{K}^{\prime}$ is a constant and $\mathrm{y}$ is the number of inhibitor molecules occupying one active site.

A tracing of $\operatorname{Ln}(\theta / 1-\theta)$ versus $\operatorname{Ln} C$ gives a straight line of slope $y$ and the intercept of $\mathrm{Ln} \mathrm{K}^{\prime}$, as presented in Fig. 10. The equilibrium constant corresponding to the adsorption isotherm is given by $K_{a d s}=\left(K^{\prime}\right)^{1 / y}$, when the value of $y>1$. This implies the formation of inhibitors multilayers onto the metal surface; and when the value of $y<1$, this means that the inhibitor molecules will occupy more than one active site.

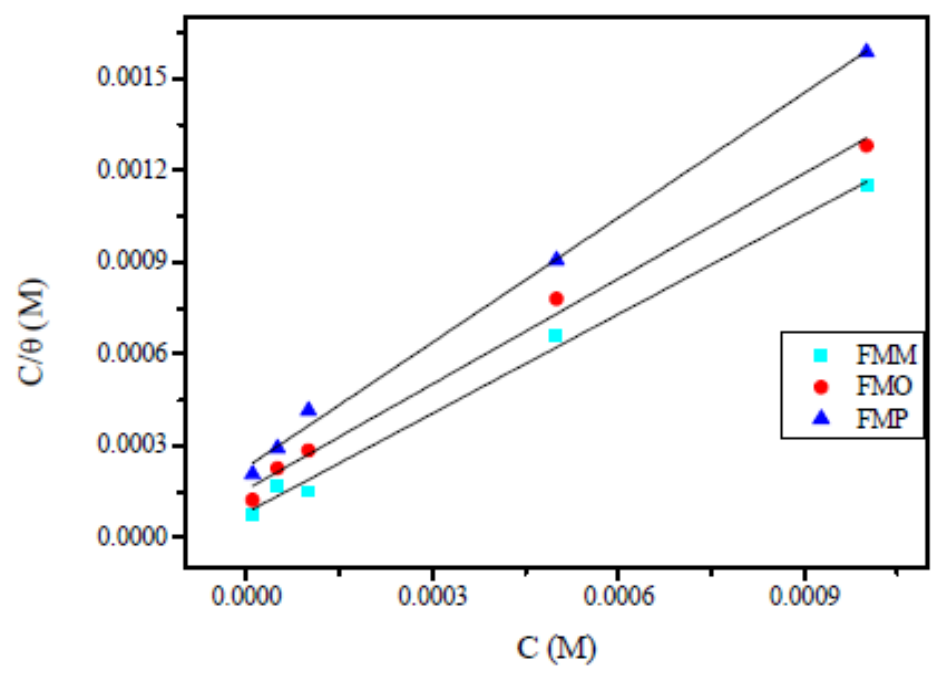

Figure 9. Langmuir adsorption isotherm model for mild steel, in $1.0 \mathrm{M} \mathrm{HCl}$, with Schiff base derivatives, at $308 \mathrm{~K}$.

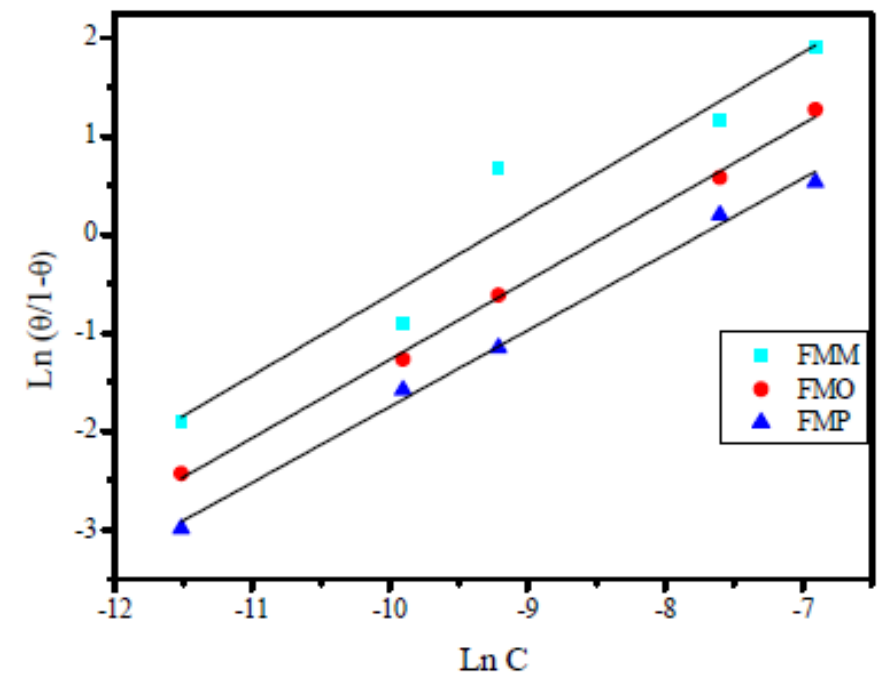

Figure 10. El-Awady et al. [43] Kinetic/thermodynamic isotherm for Schiff base derivatives in $1.0 \mathrm{M} \mathrm{HCl}$, at $308 \mathrm{~K}$.

All the adsorption parameters derived from Figs. 9 and 10 are listed in Table 4 The behavior of equilibrium constants harvested from Langmuir model was similar to the values which were collected by El-Awady kinetic-thermodynamic model. The free energy of adsorption, $\Delta G_{a d s}^{\circ}$, can also be calculated using the equation (11). 
Table 4. Adsorption parameters from Langmuir and El-Awady et al. [43]. Kinetic/thermodynamic isotherms for mild steel, in $1.0 \mathrm{M} \mathrm{HCl}$, in the absence and presence of different concentrations of Schiff base derivatives, at $308 \mathrm{~K}$.

\begin{tabular}{|c|c|c|c|c|c|c|c|c|}
\hline \multirow{2}{*}{ Inhibitors } & \multicolumn{4}{|c|}{ Langmuir } & \multicolumn{3}{|c|}{ El-Awady et al. [43] } \\
\cline { 2 - 10 } & $\begin{array}{c}\text { Kads } \\
\left(\mathbf{M}^{-\mathbf{1}}\right)\end{array}$ & $\begin{array}{c}\Delta G_{a d s}^{\circ} \\
(\mathbf{k J} \text { mol-1) }\end{array}$ & Slopes & $\mathrm{R}^{2}$ & $\begin{array}{c}\text { Kads } \\
\left(\mathbf{M}^{-\mathbf{1}}\right)\end{array}$ & $\begin{array}{c}\Delta G_{a d s}^{\circ} \\
\left(\mathbf{k J ~ m o l}^{\mathbf{1}}\right)\end{array}$ & $1 / \mathrm{y}$ & $\mathrm{R}^{2}$ \\
\hline FMP & 4331.52 & -31.72 & 1.36 & 0.996 & 3159.80 & -30.92 & 1.29 & 0.994 \\
\hline FMO & 6319.23 & -32.69 & 1.15 & 0.992 & 4413.23 & -31.77 & 1.25 & 0.997 \\
\hline FMM & 12137.16 & -34.36 & 1.08 & 0.993 & 10609.05 & -34.02 & 1.22 & 0.921 \\
\hline
\end{tabular}

As shown in Table 4, 1/y values are higher than the unity, implying that FMM, FMO and FMP inhibitor species occupied more than one active site on the mild steel surface. In addition, $\mathrm{K}_{\mathrm{ads}}$ follows the order: FMM > FMO > FMP. Generally, $\mathrm{K}_{\mathrm{ads}}$ high values mean that the inhibitor is easily and strongly adsorbed onto the metal surface, which then results in a better inhibition. This is consistent with $\eta$ values shown in Table 3.

Table 5. Effect of temperature on mild steel corrosion rate $(v)$ and percentage inhibition $(\eta \%)$, in a $1.0 \mathrm{M} \mathrm{HCl}$ solution, without and with optimum concentration $\left(1.0 \times 10^{-3} \mathrm{M}\right)$ of Schiff base derivatives.

\begin{tabular}{|c|c|c|c|}
\hline Medium & Temp & $\boldsymbol{v}$ & $\boldsymbol{\eta}$ \\
\hline \multirow{4}{*}{ Blank } & 313 & 1.678 & - \\
\cline { 2 - 4 } & 323 & 2.137 & - \\
\cline { 2 - 4 } & 333 & 3.214 & - \\
\cline { 2 - 4 } & 343 & 4.932 & - \\
\hline \multirow{4}{*}{ FMO } & 313 & 0.765 & 54 \\
\cline { 2 - 4 } & 323 & 1.163 & 45 \\
\cline { 2 - 4 } & 333 & 1.952 & 39 \\
\cline { 2 - 4 } & 343 & 3.773 & 23 \\
\hline \multirow{4}{*}{ FMM } & 313 & 0.567 & 66 \\
\cline { 2 - 4 } & 323 & 0.991 & 53 \\
\cline { 2 - 4 } & 333 & 1.731 & 46 \\
\cline { 2 - 4 } & 343 & 3.636 & 26 \\
\hline \multirow{4}{*}{ FMP } & 313 & 0.851 & 49 \\
\cline { 2 - 4 } & 323 & 1.323 & 38 \\
\cline { 2 - 4 } & 333 & 2.138 & 33 \\
\cline { 2 - 4 } & 343 & 4.389 & 11 \\
\hline
\end{tabular}

The results presented in Table 4 indicate that the free energies values are negative. The negative values signify that FMP, FMO and FMM molecules adsorption is carried out via a mixed adsorption mechanism. The literature demonstrates that the standard Gibbs free energy of adsorption values, in an aqueous solution around -20 $\mathrm{kJ} \mathrm{mol}^{-1}$ or lower (more positive), indicate an adsorption with electrostatic interaction between the adsorbent and the adsorbate (physisorption), while those around or higher (more negative) than $-40 \mathrm{~kJ} \mathrm{~mol}^{-1}$ involve charge sharing between the molecules and the metal (chemisorption) [46]. Physisorption is consistent with electrostatic interaction between the charged molecules and a charged mild steel surface, while chemisorption is consistent with charge sharing or charge transfer from the inhibitor constituents to the metal surface, to form a coordinate type of bond. The observed range of free energies in the present study suggests that FMP, FMO and FMM adsorption onto the mild steel surface is of 
"mixed mode". This implies that FMP, FMO and FMM adsorption onto mild steel, in a $1.0 \mathrm{M} \mathrm{HCl}$ solution, involves both physisorption and chemisorption processes $[47,48]$.

\section{Effect of temperature}

Table 5 shows the effect of temperature on mild steel percentage inhibition ( $\eta \%)$ and corrosion rate $(v)$, in a $1.0 \mathrm{M} \mathrm{HCl}$ solution, without and with optimum concentration $\left(1.0 \times 10^{-3} \mathrm{M}\right)$ of Schiff base derivatives.

The results depicted in Table 5 show that higher temperatures lead to an increase in the mild steel dissolution and corrosion rate, for inhibited and blank solutions. The effect of temperature on metallic dissolution in an inhibited solution is highly complex, because, at elevated temperatures, several changes, such as rapid etching, desorption and decomposition and/or rearrangement of the inhibitor substance, take place. Arrhenius equation (13) and transition state equation (14) were used [49] to calculate the activation thermodynamic parameters of the corrosion process, such as the apparent activation corrosion energy, $\left(E_{a}\right)$, the entropy of activation $\left(\Delta \mathrm{S}_{\mathrm{a}}\right)$ and the enthalpy of activation $\left(\Delta \mathrm{H}_{\mathrm{a}}\right)$ :

$$
\begin{aligned}
& v=k \exp \left(-\frac{E_{a}}{R T}\right) \\
& v=\frac{R T}{N h} \exp \left(\frac{\Delta S_{a}}{R}\right) \exp \left(-\frac{\Delta H_{a}}{R T}\right)
\end{aligned}
$$

where $E_{a}$ is the apparent activation corrosion energy expressed in $\mathrm{KJ} \mathrm{mol}^{-1}, \mathrm{R}$ is the universal gas constant expressed in $\mathrm{J} \mathrm{mol}^{-1} \mathrm{~L}^{-1}, \mathrm{k}$ is the Arrhenius preexponential factor, $\mathrm{h}$ is Plank's constant, $\mathrm{N}$ is Avogrado's number, $\Delta \mathrm{S}_{\mathrm{a}}$ is the entropy of activation and $\Delta \mathrm{H}_{\mathrm{a}}$ is the enthalpy of activation.

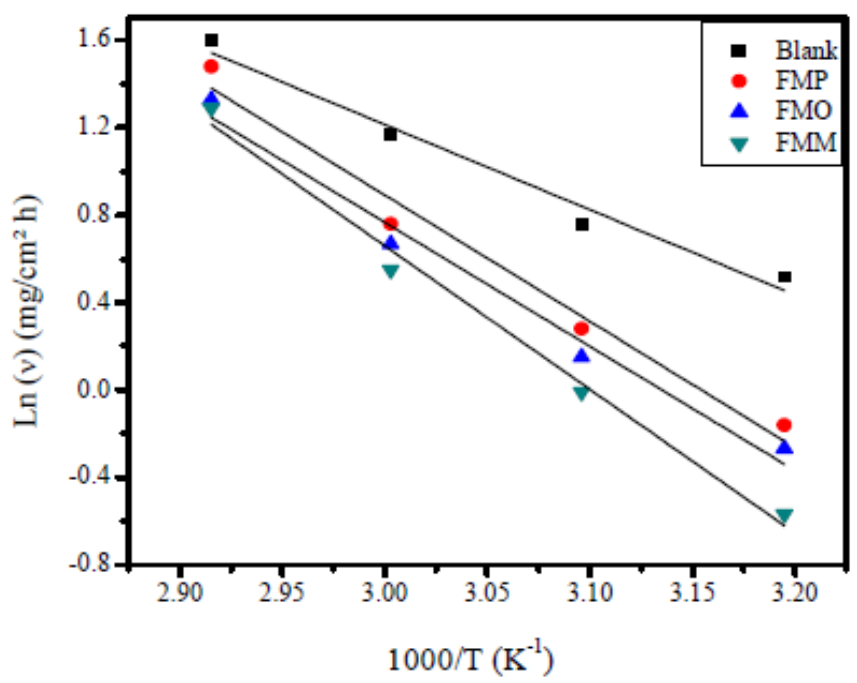

Figure 11. Arrhenius plots, in the absence and presence of optimum concentration $\left(1.0 \times 10^{-3} \mathrm{M}\right)$ of FMO, FMM and FMP, for mild steel in a $1.0 \mathrm{M} \mathrm{HCl}$ solution.

Arrhenius plots for mild steel corrosion rate $(v)$ are presented in Fig. 11. The values of apparent activation energy of corrosion $\left(E_{a}\right)$ for mild steel in $1.0 \mathrm{M} \mathrm{HCl}$, with FMP, FMO and FMM absence and presence, at optimum concentration 
$\left(1.0 \times 10^{-3} \mathrm{M}\right)$, were determined from the slope of $\operatorname{Ln}(v)$ versus $1 / \mathrm{T}$ plots, being shown in Table 6.

Table 6. Activation parameters for mild steel dissolution in $1.0 \mathrm{M} \mathrm{HCl}$, in the absence and presence of FMO, FMM and FMP at optimum concentration $\left(1.0 \times 10^{-3} \mathrm{M}\right)$.

\begin{tabular}{|c|c|c|c|c|}
\hline Medium & $\begin{array}{c}\text { Linear regression } \\
\text { coefficient }(\boldsymbol{r})\end{array}$ & $\begin{array}{c}\boldsymbol{E}_{\boldsymbol{a}} \\
\left(\mathbf{k J ~ m o l}^{\mathbf{1}}\right)\end{array}$ & $\begin{array}{c}\Delta \boldsymbol{H}_{\boldsymbol{a}} \\
\left(\mathbf{k J ~ m o l}^{\mathbf{1}}\right)\end{array}$ & $\begin{array}{c}\Delta \boldsymbol{S}_{\boldsymbol{a}} \\
\left(\mathbf{J ~ m o l}^{-\mathbf{1}} \mathbf{K}^{-\mathbf{1}}\right)\end{array}$ \\
\hline Blank & 0.96788 & 32.38 & 29.66 & -146.35 \\
\hline FMO & 0.97542 & 47.19 & 44.47 & -106.04 \\
\hline FMM & 0.98543 & 54.60 & 51.88 & -84.70 \\
\hline FMP & 0.96808 & 48.03 & 45.31 & -102.49 \\
\hline
\end{tabular}

Table 6 shows that $\mathrm{E}_{\mathrm{a}}$ values, in FMO, FMM and FMP presence, are higher than those of the uninhibited acid solution $\left(32.38 \mathrm{KJ} \mathrm{mol}^{-1}\right)$. The fact that the activation energy, in the inhibitor presence, is higher was explained in different ways in the literature. According to Riggs and Hurd [50], the decrease in apparent activation energy $\left(E_{a}\right)$, at higher inhibition levels, arises from a shift in the net corrosion reaction, from one on the uncovered surface to one directly involving the adsorbed sites. This also reveals that the entire process is surface-reaction controlled, since the corrosion process energy of activation $\left(\mathrm{E}_{\mathrm{a}}\right)$, both in the inhibitor molecule absence and presence, was higher than $20 \mathrm{~kJ} \mathrm{~mol}^{-1}$ [51]. Szauer and Brand [51] explained that the increase in the activation energy could be due to an appreciable decrease in the inhibitor molecule adsorption onto the mild steel surface, at higher temperatures [52]. The increase in activation energy, after FMP, FMO and FMM addition to the $1.0 \mathrm{M} \mathrm{HCl}$ solution, can indicate that physical (electrostatic) adsorption occurs in the first stage [53].

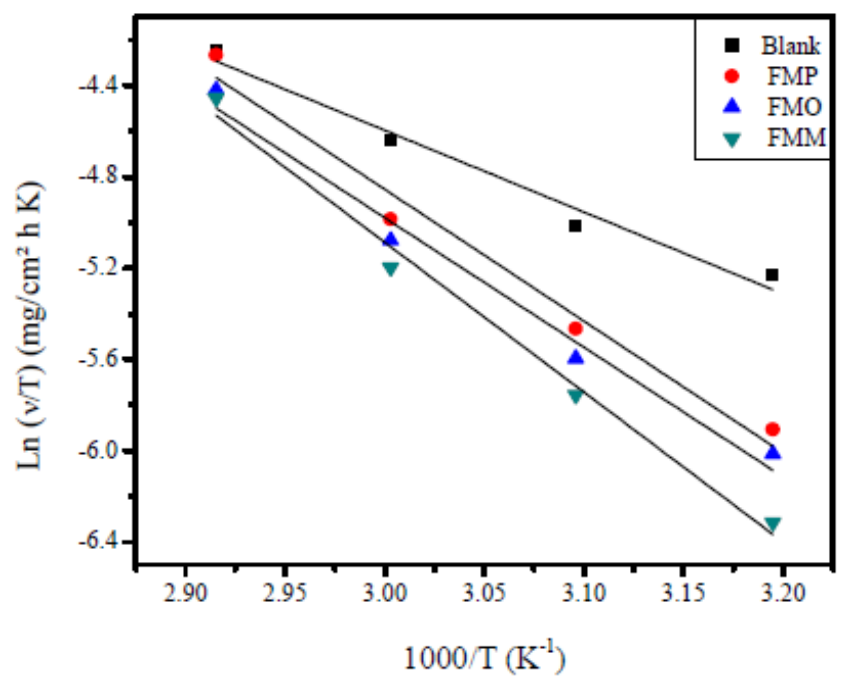

Figure 12. Transition Arrhenius plots, in FMO, FMM and FMP absence and presence, for mild steel in a $1.0 \mathrm{M} \mathrm{HCl}$ solution.

Fig. 12 shows a plot of $\operatorname{Ln}(v / \mathrm{T})$ versus $1 / \mathrm{T}$. The straight lines are obtained with a slope $\left(\Delta \mathrm{H}_{\mathrm{a}} / \mathrm{R}\right)$ and an intercept of $\left(\mathrm{Ln} \mathrm{R} / \mathrm{Nh}+\left(\Delta \mathrm{SH}_{\mathrm{a}} / \mathrm{R}\right)\right.$, from which $\Delta \mathrm{H}$ and $\Delta \mathrm{S}$ values are calculated and shown in Table 6. 
Inspection of these data revealed that the entropy of activation, $\Delta \mathrm{S}_{\mathrm{a}}$, in FMP, FMO and FMM absence and presence, is high and negative. This suggests that the activated complex, in the rate-determining step, represents an association, rather than a dissociation step, meaning that a decrease in disordering takes place on going from reactants to the activated complex [54]. $\Delta \mathrm{H}_{\mathrm{a}}$ positive sign reflects the endothermic nature of the steel dissolution process, suggesting that steel dissolution is slow [55], in FMP, FMO and FMM presence.

\section{Theoretical calculations of molecular reactivity}

\section{Quantum chemical indices}

The use of theoretical study by the Density Functional Theory (DFT) method is a very important tool for several theorists to study the inhibitor molecules reactivity [56]. This property was determined by the use of very specific descriptors in this study. The first factor is HOMO and LUMO densities. These are shown in Fig. 13, with FMO, FMM and FMP optimized molecules. From this figure, it is clear that the HOMO electronic density is located on the whole molecular surface of aminophenylimino-ethyl, while LUMO density is distributed around the 4hydroxy-6-methyl-2H-pyran-2-one ring, for the three studied molecules.

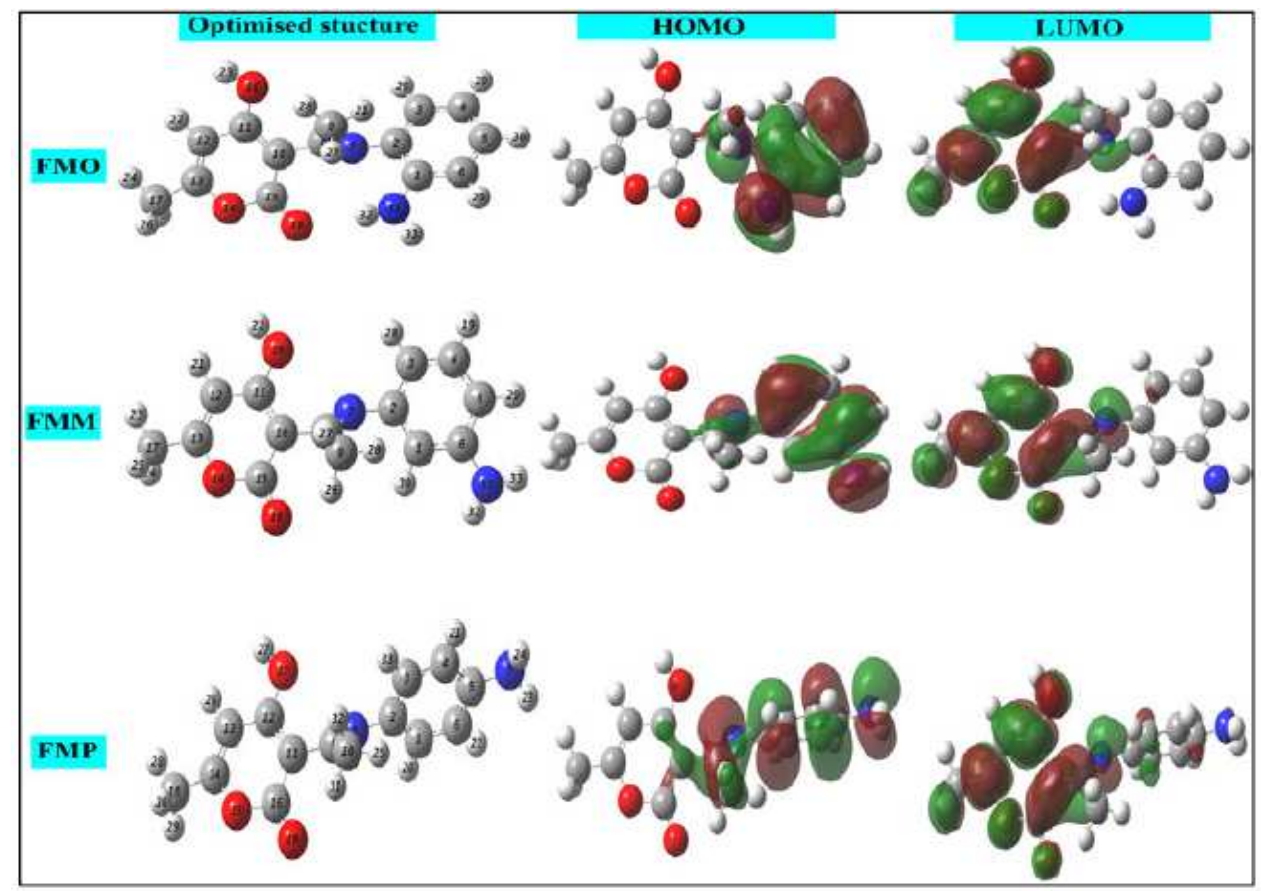

Figure 13. FMO, FMM and FMP molecules HOMO and LUMO optimized structures.

$\mathrm{E}_{\mathrm{HOMO}}$ and $\mathrm{E}_{\mathrm{LUMO}}$ energies values are calculated at the level of the B3LYP/6 -31G $(d, p)$ method, with the help of Gaussian 09 software [57, 58]. From these values, it is possible to extract different structural quantum parameters of the FMO, FMM and FMP compounds: gap energy $\left(\Delta \mathrm{E}_{\mathrm{gap}}\right)$, dipole moment $(\mu)$, electronegativity $(\square)$, hardness $(\eta)$, number of electrons transferred from the inhibitor to the metal surface, or electron transfer fraction $\left(\Delta \mathrm{N}_{110}\right)$ and the total energy $\left(\mathrm{E}_{\mathrm{T}}\right)$. These parameters are shown in Table 7. 
Table 7. FMO, FMM and FMP calculated quantum parameters.

\begin{tabular}{|c|c|c|c|c|c|c|c|c|}
\hline $\begin{array}{c}\text { parameters } \rightarrow \\
\text { Inhibitors } \boldsymbol{\nabla}\end{array}$ & $\begin{array}{c}\mathrm{E}_{\text {LUMO }} \\
(\mathbf{e V})\end{array}$ & $\begin{array}{c}\mathrm{E}_{\text {HOMO }} \\
(\mathbf{e V})\end{array}$ & $\begin{array}{c}\Delta \mathrm{E}_{\text {gap }} \\
(\mathbf{e V})\end{array}$ & $\begin{array}{c}\mu \\
(\mathbf{D})\end{array}$ & $\begin{array}{c}\eta \\
(\mathbf{e V})\end{array}$ & $\begin{array}{c}\chi \\
(\mathbf{e V})\end{array}$ & $\Delta \mathrm{N}_{110}$ & $\begin{array}{c}\mathrm{E}_{\mathrm{T}} \\
(\mathbf{u . a})\end{array}$ \\
\hline FMO & -1.498 & -4.722 & 3.224 & 7.335 & 1.612 & 3.110 & 0.530 & -877.106 \\
\hline FMM & -1.353 & -5.085 & 3.732 & 4.899 & 1.866 & 3.219 & 0.429 & -877.104 \\
\hline FMP & -1.308 & -4.844 & 3.536 & 4.232 & 1.768 & 3.076 & 0.493 & -877.102 \\
\hline
\end{tabular}

The ionization potential (IP), the electron affinity (EA) and gap energy $\left(\Delta \mathrm{E}_{\mathrm{gap}}\right)$ are found from $\mathrm{E}_{\text {HOMO }}$ and ELUMO, using equations (15), (16) and (17):

$$
\begin{aligned}
& I P=-E_{\text {HOMO }} \\
& E A=-E_{\text {LUMO }} \\
& \Delta E_{\text {gap }}=E_{\text {LUMO }}-E_{\text {HOMO }}
\end{aligned}
$$

The hardness $(\eta)$ and the electronegativity $(\square)$ are given by the following relations $[59,60]$ :

$$
\begin{aligned}
& \eta=\frac{\Delta E_{\text {gaq }}}{2} \\
& \chi=\frac{I P+E A}{2}=\eta-2 I P
\end{aligned}
$$

The fraction of transferred electrons $\left(\Delta \mathrm{N}_{110}\right)$ is calculated using equation (20) [61]:

$$
\Delta N_{110}=\frac{\varphi-x_{\text {inh }}}{2\left(\eta_{F e}+\eta_{\text {inh }}\right)}
$$

where $\varphi$ and $\chi_{\text {inh }}$ denote the inhibitor molecule work function and electronegativity, respectively; and $\eta_{\mathrm{Fe}}$ and $\eta_{\text {inh }}$ represent $\mathrm{Fe}$ absolute hardness and the inhibitor molecule, respectively. The $\Delta \mathrm{N}$ value calculation is more appropriate by the use of the $(\varphi)$ work function. Theoretically, the values obtained for the $\varphi$ function are $3.91 \mathrm{eV}, 4.82 \mathrm{eV}$ and $3.88 \mathrm{Ev}$, for the Fe (100), (110), and (111) surfaces, respectively $[62,63]$. The hardness of $\mathrm{Fe}=0$, assuming that, for a metal, IP mass = EA, because these surfaces are softer than the neutral metal atoms [64]. The main quantum parameters are shown in Table 7. In line with Frontier Molecular Orbital (FMO) theory, an inhibitor with high Еномо energy value is associated with a strong electron donating ability and, thus, with better inhibition efficiency $[65,66]$. In contrast, low ELUMO energy of a compound reflects its ability to accept electrons from the metallic surface and, therefore, higher inhibition efficiency. The gap energy $\left(\Delta \mathrm{E}_{\text {gap }}\right)$ is a very important parameter to value the degree of interactions between an inhibitor and the metal surface. That is, the low $\Delta \mathrm{E}_{\text {gap }}$ value shows that this inhibitor adsorption onto the metal surface is high [67]. Examination of the results in Table 7 shows that the FMO compound

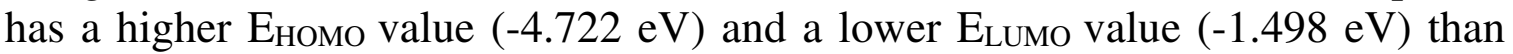
those obtained for FMP and FMM compounds, respectively. This reflects that FMO molecule ability to give and accept electrons is very significant. In addition, $\Delta \mathrm{E}_{\mathrm{gap}}$ value is low for the FMO compound; this indicates that the adsorption capacity of this inhibitor increases onto the metal surface. The dipole moment $(\mu)$ is considered as a quantity reflecting the polarity of a molecule. In the literature, 
some authors claimed that increasing the dipole moment of a molecule can lead to an increase in the adsorption performance [68]. The data in Table 7 show that FMO, FMM and FMP inhibitors dipole moment values are 7.335 D, 4.899 D, and 4.232 D, respectively; and that the evolution of the inhibitory efficiency is in the following order: FMO > FMM > FMP. Concerning the electron transfer fraction $\left(\Delta \mathrm{N}_{110}\right)$, if $\Delta \mathrm{N}_{110}<3.6$, the inhibitor performance is good and increases with the higher electron donating capacity of this molecule to the metal surface $[69,70]$. In this sense, $\Delta \mathrm{N}_{110}$ value is also recorded in Table 7 , and shows that the inhibition power resulting from electron donation is in very good agreement with Lukovits' study [71]. FMO compound has a higher value of transferred electrons, compared to those obtained for FMP and FMM, which facilitates its adsorption onto the metal surface. Finally, the minimum value of FMO total energy $\left(\mathrm{E}_{\mathrm{T}}\right)$ indicates that this compound is well adsorbed onto the studied mild steel surface. This result is overlapping with the following order of inhibition efficiency: FMO > FMM > FMP. This order of inhibition efficiency did not match with those obtained using electrochemical techniques, weight loss, and Monte Carlo simulation, because it resulted from the very close values of the compounds total energy (ET), which were -877.106 , -877.104, and -877.102 for FMO, FMM and FMP, respectively, and this difference was 0.002 between one compound and the others.

\section{Active sites of the inhibitor molecules}

An organic molecule is considered a good metal corrosion inhibitor, if it carries atoms and heteroatoms responsible for nucleophilic and/or electrophilic attack [72]. For this reason, we have used very popular methods, such as Mulliken's atomic charges and Fukui's indices (listed in Table 8). Atoms bearing negative Mulliken charges are considered as electron donor sites (Nucleophiles), when interacting with the iron surface, to form coordination bonds. Therefore, Table 8 shows that the oxygen and nitrogen atoms are carrying more negative atomic charges for the three FMO, FMM and FMP compounds, at the same time, according to the following sequence: N7, O14, O16, O18, and N31; whereas the $\mathrm{C} 11, \mathrm{C} 13$, and $\mathrm{C} 15$ carbon atoms carry high density of positive charges. This indicates that these atoms are considered electron acceptor active sites from iron $\mathrm{d}$ orbital, forming retro-donation bonds. The Fukui function $(f(\vec{r}))$ is calculated according to equation (21) [73]:

$$
f(\vec{r})=\left(\frac{\partial \rho(\vec{r})}{\partial N}\right)_{V(\vec{r})}
$$

The nucleophilic and electrophilic attack Fukui functions, $f(\vec{r})^{+}$and $f(\vec{r})^{-}$, respectively, can be calculated as follows [19]:

$$
\begin{aligned}
& f_{i}(\vec{r})^{+}=q_{i}(N+1)-q_{i}(N) \\
& f_{i}(\vec{r})^{-}=q_{i}(N)-q_{i}(N-1)
\end{aligned}
$$

where $q_{i}(N+1), q_{i}(N)$ and $q_{i}(N-1)$ are the charge values of $i$ atom, forh cation, neutral and anion, respectively. 
The studied Fukui functions values are calculated by the Materials Studio 8 software, from Biovia-Accelrys Inc., using the $\mathrm{Dmol}^{3}$ module. The calculations were performed using the correlation BOP function and the digital double polarization (DNP).

Table 8. Mulliken atomic charge distribution and Fukui functions for the FMO, FMM and FMP compounds.

\begin{tabular}{|c|c|c|c|c|c|c|c|c|c|}
\hline \multirow{2}{*}{ Atoms } & \multicolumn{3}{|c|}{ Mulliken charges } & \multicolumn{3}{c|}{$f(\vec{r})^{+}$} & \multicolumn{3}{c|}{$f(\vec{r})^{-}$} \\
\cline { 2 - 10 } & FMO & FMM & FMP & FMO & FMM & FMP & FMO & FMM & FMP \\
\hline C1 & 0.226 & -0.136 & -0.039 & 0.009 & 0.003 & 0.010 & 0.023 & 0.034 & 0.029 \\
\hline C2 & 0.145 & 0.218 & 0.195 & -0.021 & -0.021 & -0.021 & 0.055 & 0.023 & 0.049 \\
\hline C3 & -0.056 & -0.089 & -0.058 & 0.005 & 0.006 & 0.006 & 0.020 & 0.091 & 0.024 \\
\hline C4 & -0.032 & 0.010 & -0.076 & 0.007 & 0.005 & 0.007 & 0.058 & 0.005 & 0.039 \\
\hline C5 & -0.020 & -0.096 & 0.248 & 0.011 & 0.013 & 0.016 & 0.027 & 0.075 & 0.025 \\
\hline C6 & -0.075 & 0.269 & -0.070 & 0.005 & 0.008 & 0.007 & 0.036 & 0.014 & 0.034 \\
\hline N7 & -0.332 & -0.313 & -0.390 & 0.027 & 0.030 & 0.018 & 0.047 & 0.038 & 0.096 \\
\hline C8 & 0.218 & 0.217 & 0.195 & -0.010 & -0.008 & -0.007 & 0.016 & 0.027 & 0.045 \\
\hline C9 & -0.120 & -0.132 & -0.133 & -0.011 & -0.012 & -0.010 & -0.008 & -0.003 & -0.009 \\
\hline C10 & -0.103 & -0.102 & -0.097 & 0.069 & 0.070 & 0.066 & -0.025 & -0.025 & -0.030 \\
\hline C11 & 0.380 & 0.379 & 0.381 & 0.088 & 0.085 & 0.081 & 0.021 & 0.017 & 0.020 \\
\hline C12 & -0.153 & -0.151 & -0.153 & 0.016 & 0.016 & 0.017 & 0.002 & -0.001 & -0.002 \\
\hline C13 & 0.336 & 0.334 & 0.336 & 0.099 & 0.098 & 0.094 & 0.009 & 0.011 & 0.014 \\
\hline O14 & -0.492 & -0.494 & -0.495 & 0.068 & 0.072 & 0.067 & 0.015 & 0.011 & 0.016 \\
\hline C15 & 0.521 & 0.510 & 0.508 & 0.038 & 0.035 & 0.032 & 0.009 & 0.007 & 0.009 \\
\hline O16 & -0.448 & -0.437 & -0.437 & 0.065 & 0.068 & 0.062 & -0.001 & -0.012 & -0.008 \\
\hline C17 & -0.099 & -0.098 & -0.098 & -0.028 & -0.028 & -0.027 & -0.006 & -0.006 & -0.007 \\
\hline O18 & -0.447 & -0.447 & -0.444 & 0.103 & 0.095 & 0.089 & -0.007 & 0.018 & 0.026 \\
\hline N31 & -0.429 & -0.391 & -0.318 & -0.002 & 0.011 & 0.029 & 0.127 & 0.104 & 0.066 \\
\hline & & & & & & & & & \\
\hline
\end{tabular}

Generally, $f(\vec{r})^{+}$and $f(\vec{r})^{-}$high values indicate the high capacity of the atom to gain and lose electrons, respectively. From Table 8, on the nucleophilic attack, the most reactive sites are $\mathrm{C} 2, \mathrm{C} 3, \mathrm{C} 4, \mathrm{C} 6, \mathrm{~N} 7$ and $\mathrm{N} 31$, for the three studied compounds. On the other hand, the $\mathrm{C} 10, \mathrm{C} 11, \mathrm{C} 13, \mathrm{O} 14$ and $\mathrm{O} 18$ atoms can accept electrons from the metal surface. The sites responsible for both attacks are shown in Fig. 14.

\section{Effect of protonation on quantum parameters}

The studied compounds have several active sites available for protonation, but, in this work, we chose the nitrogen atom (N31) of the aminophenyl group, as a more favorable site for protonation. Our choice is based on considerations such as the theoretical calculation of $\mathrm{pH}, \mathrm{pKa}$ and proton affinity (PA). PA is calculated from the studied compounds total energies, according to the following equation: 
$P A=E_{T}$ (protonated inhibitor $)-E_{T}($ inhibitor $)-E_{T}\left(H_{3} O^{+}\right)+E_{T}\left(H_{2} O\right)$

PA is a very important descriptor for determining the chemical reactivity of a molecule. Indeed, this molecule reactivity increases when the PA value is high. Table 9 summarizes the different chemical quantum parameters values of protonated and unprotonated FMO, FMM and FMP molecules.
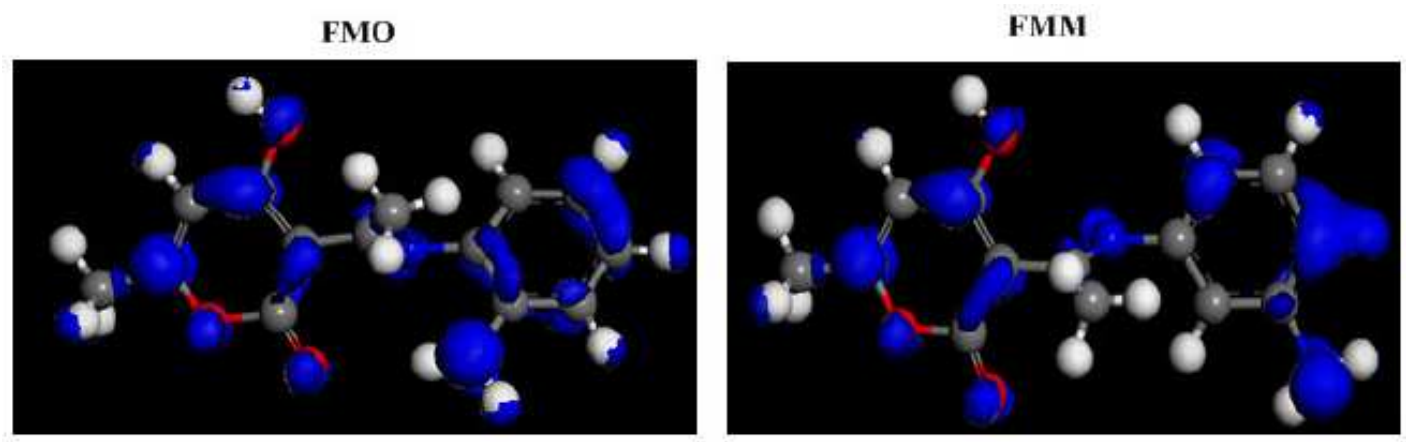

FMP

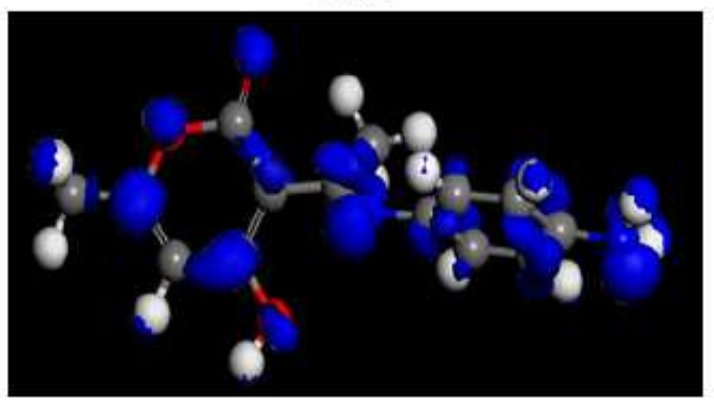

Figure 14. Electron donor and acceptor assets for the studied molecules.

Table 9 shows that after FMO, FMM and FMP compounds protonation, their

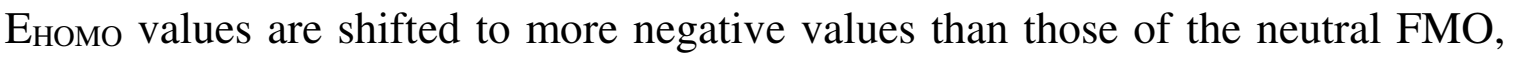
FMM and FMP molecules. This indicates that the protonated forms of the test compounds have an ability to accept electrons [74]. We have also noted, from Table 9 , that the electron donor capacity $\left(\Delta \mathrm{N}_{110}\right)$ of the studied protonated molecules was decreased and negative, compared to the non-protonated forms. This means that donating electrons from the inhibitory molecules to the metal surface is no longer possible [74]. These results are probably due to the electrostatic effect between the positively charged molecules and the chlorine ions adsorbed onto the iron surface.

As shown in Table 9, the proton affinity values are more negative for the FMO protonated compound. This indicates that this compound is more reactive than FMM and FMP compounds.

The molecular reactivity of the tested products is in the following order: $\mathrm{RM}(\mathrm{FMO})>\mathrm{RM}(\mathrm{FMM})>\mathrm{RM}(\mathrm{FMP})$. The polarity of the studied molecules is totally changed after the protonation, and is done in the following order: $\mu(\mathrm{FMO})$ $>\mu(\mathrm{FMM})>\mu(\mathrm{FMP})$. This result does not agree with the inhibition efficiency. 
Table 9. Different values of the quantum parameters of protonated and unprotonated molecules (FMO, FMM and FMP).

\begin{tabular}{|c|c|c|c|c|c|c|c|}
\hline Inhibitors & $\begin{array}{c}\boldsymbol{P A} \\
\left(\mathbf{K c a l ~ m o l}^{-1}\right)\end{array}$ & $\begin{array}{c}\boldsymbol{E}_{\text {LUMO }} \\
(\mathbf{e V})\end{array}$ & $\begin{array}{c}\boldsymbol{E}_{\text {HOMo }} \\
(\mathbf{e V})\end{array}$ & $\begin{array}{c}\Delta \text { Egap } \\
(\mathbf{e V})\end{array}$ & $\begin{array}{c}\boldsymbol{\mu} \\
(\mathbf{D})\end{array}$ & $\begin{array}{c}\Delta N 110 \\
(\mathbf{e V})\end{array}$ & $\begin{array}{c}\boldsymbol{E}_{\boldsymbol{T}} \\
(\mathbf{u . a})\end{array}$ \\
\hline FMO & - & -1.498 & -4.722 & 3.224 & 7.335 & 0.530 & -877.106 \\
\hline FMO(N31) H & -426.706 & -4.973 & -9.243 & 4.270 & 1.025 & -0.5358 & -877.510 \\
\hline FMM & - & -1.353 & -5.085 & 3.732 & 4.899 & 0.429 & -877.104 \\
\hline FMM(N31) H+ & -405.371 & -4.169 & -8.523 & 4.354 & 15.393 & 0.350 & -877.474 \\
\hline FMP & - & -1.308 & -4.844 & 3.536 & 4.232 & 0.493 & -877.102 \\
\hline FMP(N31) H & -405.370 & -3.989 & -8.463 & 4.474 & 18.915 & -0.314 & -877.472 \\
\hline
\end{tabular}

\section{Monte Carlo simulations}

The interaction between the investigated inhibitors (FMO, FMM and FMP) and $\mathrm{Fe}(110)$ plane surface was carried out using Monte Carlo simulations. The adsorption locator code implemented in the Material Studio 8.0 software, from Biovia-Accelrys Inc. USA, was adopted in this simulation. The COMPASS (condensed phase optimized molecular potentials for atomistic simulation studies) force field was used for the simulation of all molecules and systems.

The simulation of the corrosion inhibitor molecules designated as FMM, FMO and FMP, on the Fe(110) surface, was carried out in order to locate the low energy adsorption sites of the potential corrosion inhibitors on the Fe surface. MD simulations were performed in a NVT canonical ensemble, at $308 \mathrm{~K}$, with a time step of $1.0 \mathrm{fs}$ and a total simulation time of $1000 \mathrm{ps}$, using an Anderson thermostat. Interaction energies (adsorption energy) $\left(\mathrm{E}_{\mathrm{int}}\right)$ between the inhibitor molecules and the $\mathrm{Fe}(110)$ surface were calculated using the following equation [75-80]:

$$
E_{\text {ine }}=E_{\text {total }}-\left(E_{F q-\text { surface }}+E_{\text {in } h}\right)
$$

Where Etotal is the total energy of an inhibitor molecule and of the metal surface system, E $\mathrm{E}_{\mathrm{Fe}-\text { surface }}$ is the energy of the Fe surface, without the adsorption of any inhibitor molecule, and $E_{\text {inh }}$ represents the energy of isolated inhibitor molecules (FMO, FMM and FMP). It is important to note that the binding energy ( $E_{\text {binding }}$ ) is the negative value of the interaction energy, being calculated according to the following equation:

$$
E_{\text {binding }}=-E_{\text {int }}
$$

Nowadays, Molecular Dynamics Simulation (MDS) approach is known as one of the useful tools which are considered to investigate the adsorption behaviors of inhibitor molecules onto metal surfaces. In order to determine the more suitable adsorption configuration of FMM, FMO and FMP molecules, we have considered the above mentioned approach. Calculated total energy, adsorption energy, rigid adsorption energy, and deformation energy values are shown in Table 10.

The most stable adsorption configurations of FMM, FMO and FMP molecules on the $\mathrm{Fe}(110)$ surface are depicted in Fig. 15. 
Table 10. Outputs and descriptors calculated by Monte Carlo simulation, for FMM, FMO and FMP adsorption onto the $\mathrm{Fe}(110)$ surface, in gas phase (in kcal mol${ }^{-1}$ ).

\begin{tabular}{|c|c|c|c|c|c|}
\hline Systems & $\begin{array}{c}\text { Total } \\
\text { energy }\end{array}$ & $\begin{array}{c}\text { Adsorption } \\
\text { energy }\end{array}$ & $\begin{array}{c}\text { Rigid } \\
\text { adsorption } \\
\text { energy }\end{array}$ & $\begin{array}{c}\text { Deformation } \\
\text { energy }\end{array}$ & $\begin{array}{c}\text { dEad/dNi } \\
\text { inhibitor }\end{array}$ \\
\hline Fe(110) + FMM & $\begin{array}{c}- \\
256.293\end{array}$ & -148.823 & -152.146 & 3.322 & -148.823 \\
\hline Fe(110) + FMO & $\begin{array}{c}- \\
262.502\end{array}$ & -148.773 & -152.048 & 3.275 & -148.773 \\
\hline $\mathbf{F e}(\mathbf{1 1 0})+\mathbf{F M P}$ & $\begin{array}{c}- \\
219.669\end{array}$ & -144.431 & -151.037 & 6.605 & -144.431 \\
\hline
\end{tabular}

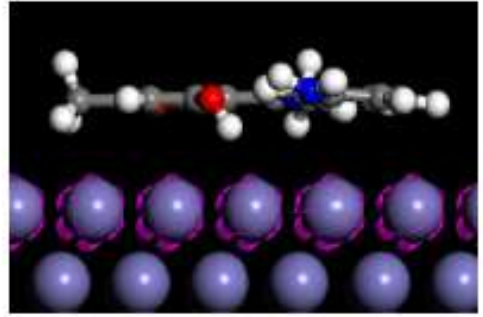

(a) $\mathrm{Fe}(110)+\mathrm{FMM}$

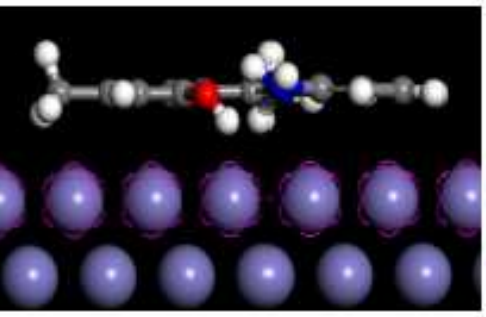

(b) $\mathrm{Fe}(110)+\mathrm{FMO}$

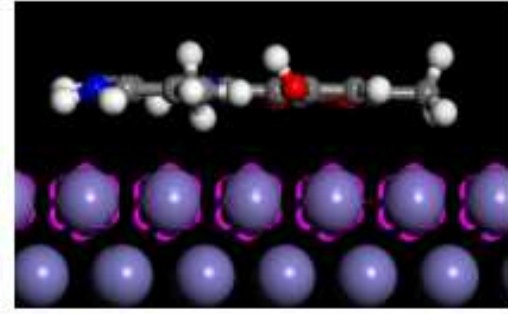

(c) $\mathrm{Fe}(110)+\mathrm{FMP}$

Figure 15. Side views of the most stable configurations, for the adsorption of (a) FMM, (b) FMO and (c) FMP, on the Fe(110) surface, calculated using Monte Carlo simulations.

Higher negative adsorption energy values indicate a more stabilized and stronger interaction between a metal and an inhibitor molecule. In other words, it can be said that a larger $E_{\text {binding }}$ value implies that the corrosion inhibitor combines more easily and tightly with the iron surface, and that the inhibitive performance is higher and spontaneous [81]. The calculated interaction energy values for FMM, FMO and FMP inhibitors were -148.823, -148.773 and -144.431 kcal mol-1, respectively. It is apparent, from these values and information given above, that FMM has the highest interaction energy value and corrosion protection capability among the studied inhibitor molecules (FMO, FMM and FMP). According to the calculated interaction and binding energy values, the corrosion inhibition efficiency ranking of the studied molecules can be given as follows:

FMM $>$ FMO > FMP; and this ranking is in good agreement with the experimental inhibition efficiency values.

\section{Conclusions}

The inhibition efficiency increased with higher concentrations, but decreased with the increase in temperature, and the order of inhibition efficiency decreased as follows: FMM > FMO > FMP. Tafel polarization curves indicated that the corrosion current density decreased with the inhibitor molecules addition, while the corrosion potential has slightly changed. Therefore, the Schiff base derivatives can be described as mixed type inhibitors, for mild steel, in a $1.0 \mathrm{M} \mathrm{HCl}$ solution. EIS results show that $\mathrm{C}_{\mathrm{dl}}$ values tend to decrease, and that both $\mathrm{R}_{\mathrm{ct}}$ and $\eta \%$ tend to increase, with higher inhibitors concentrations. These results can be attributed to 
an increase in the thickness of the protective film formed on the mild steel surface. FMM, FMO and FMP were found to obey Langmuir adsorption isotherm and thermodynamic- kinetic model of El-Awady, from the fit of experimental data. The adsorption equilibrium constants values suggest that these inhibitors are strongly adsorbed onto the mild steel surface. The free energy of adsorption values indicate that it is a mixed physical and chemical adsorption. The results obtained from the theoretical studies provided good corroborative explanations of the experimental results.

\section{References}

1. Mohsen L, Mohammad RA, Somaieh M. The enhancing power of iodide on corrosion prevention of mild steel in the presence of asynthetic-soluble Schiffbase: Electrochemical and surface analyses. Electrochim Acta. 2010;55: 60586063. https://doi.org/10.1016/j.electacta.2010.05.066

2. Yurchenko R, Pogrebova L, Pilipenko T, et al. Anticorrosive properties of Nacetylmethylpyridinium bromides. Russ J Appl Chem. 2006;79:1100-1104. https://doi.org/10.1134/S1070427206070111

3. Zarrok H, Oudda H, El Midaoui A, et al. Some new bipyrazole derivatives ascorrosion inhibitors for C38 steel in acidic medium. Res Chem Intermed. 2012;38:2051-2063. https://doi.org/10.1007/s11164-012-0525-X

4. Zarrouk A, Hammouti B, Zarrok H, et al. Corrosion Inhibition of Copper inNitric Acid Solutions Using a New Triazole Derivative. Int J Electrochem. Sci. 2012;6:89-105.

5. Zarrouk A, Hammouti B, Dafali A, et al. L-Cysteine Methyl Ester Hydrochloride: A New Corrosion Inhibitor for Copper in Nitric Acid. Der Pharm Chem. 201;3(4):266-274.

6. Zarrok H, Zarrouk A, Salghi R, et al. Gravimetric and quantum chemical studies of 1-[4-acetyl-2-(4-chlorophenyl)quinoxalin-1(4H)-yl]acetone as corrosion inhibitor for carbon steel inhydrochloric acid solution. J Chem Pharm Res. 2012;4:5056-5066.

7. Bentiss F, Lagrenee M, Traisnel M, et al. The corrosion inhibition of mild steel inacidic media by a new triazole derivative. Corros Sci. 1999;4:789-803. https://doi.org/10.1016/S0010-938X(98)00153-X

8. Quraishi MA, Shukla SK. Poly(aniline-formaldehyde): a new and effective corrosion inhibitor for mild steel inhydrochloric acid. Mater Chem Phys. 2009;113:685-689. https://doi.org/10.1016/j.matchemphys.2008.08.028

9. Ansari FA, Quraishi MA. Inhibitive effect of some gemini surfactants as corrosion inhibitors for mild steel inacetic acid media. Arab J Sci Eng. 2011;36:11-20. https://doi.org/10.1007/s13369-010-0008-6

10. Oguize EE, Li Y, Wang SG, et al. Understanding corrosion inhibition mechanisms-experimental and theoretical approach. RSC Adv. 2011;1:866873. https://doi.org/10.1039/C1RA00148E

11. Goulart CM, Esteves-Souza A, Martinez-Huitle CA, et al. Experimental and theoretical evaluation of semicarbazones and thiosemicarbazones asorganic 
corrosion inhibitors. Corros Sci. 2013;67:281-291. https://doi.org/10.1016/j.corsci.2012.10.029

12. Gopiraman M, Selvakumaran N, Kesavan D, et al. Adsorption and corrosion inhibition behaviour of $\mathrm{N}$-(phenylcarbamothioyl)benzamide on mild steel inacidic medium. Prog Org Coat. 2012;73:104-111. https://doi.org/10.1016/j.porgcoat.2011.09.006

13. Ghazoui A, Zarrouk A, Bencaht $\mathrm{N}$, et al. New possibility of mild steel corrosion inhibition by organic heterocyclic compound. J. Chem. Pharm. Res. 2014; 6: 704-712.

14. Zarrok H, Zarrouk A, Salghi R, et al. Inhibitive properties and thermodynamic characterization of quinoxaline derivative on carbon steel corrosion in acidic medium. Der Pharm Lett. 2013;5:43-53.

15. Belayachi M, Serrar H, Zarrok H, et al. New pyrimidothiazine Derivative as Corrosion Inhibitor for Carbon Steel in Acidic Media. Int J Electrochem Sci. 2015;10:3010-3025.

16. Daoud D, Douadi T, Issaadi S, et al. Adsorption and corrosion inhibition of new synthesized thiophene Schiff base on mild steel $\mathrm{X} 52$ in $\mathrm{HCl}$ and $\mathrm{H}_{2} \mathrm{SO}_{4}$ solutions. Corros

Sci. 2014;79:50-58. https://doi.org/10.1016/j.corsci.2013.10.025

17. Issaadi S, Douadi T, Zouaoui A, et al. Novel thiophene symmetrical Schiff base compounds as corrosion inhibitor for mild steel in acidic media. Corros Sci. 2011;53:1484-1488. https://doi.org/10.1016/j.corsci.2011.01.022

18. Solmaz R, Altunbas E, Kardas G. Adsorption and corrosion inhibition effect of 2-((5-mercapto-1,3,4-thiadiazol-2-ylimino)methyl)phenol Schiff base on mild steel. Mater Chem Phys. 2011;125:796-801. https://doi.org/10.1016/j.matchemphys.2010.09.056

19. Deng S, Li X, Xie X. Hydroxymethyl urea and 1,3-bis(hydroxymethyl) urea as corrosion inhibitors for steel in $\mathrm{HCl}$ solution. Corros Sci. 2014;80:276-289. https://doi.org/10.1016/j.corsci.2013.11.041

20. Hasanov R, Sadıkoğlu M, Bilgiç S. Electrochemical and quantum chemical studies of some Schiff bases on the corrosion of steel in $\mathrm{H}_{2} \mathrm{SO}_{4}$ solution. Appl Surf Sci. 2007;253:3913-3921. https://doi.org/10.1016/j.apsusc.2006.08.025

21. Prabhu RA, Venkatesha TV, Shanbhag AV, et al. Inhibition effects of some Schiff's bases on the corrosion of mild steel inhydrochloric acid solution. Corros Sci. 2008;50:3356-3362. https://doi.org/10.1016/j.corsci.2008.09.009

22. Zarrouk A, Zarrok H, Ramli Y, et al. Inhibitive properties, adsorption and theoretical study of 3,7-dimethyl-1-(prop-2-yn-1-yl)quinoxalin-2(1H)-one as efficient corrosion inhibitor for carbon steel in hydrochloric acid solution. $\mathbf{J}$ Mol Liq. 2016;222:239-252. https://doi.org/10.1016/j.molliq.2016.07.046

23. ASTM, G 31-72, American Society for Testing and Materials, Philadelphia, PA, 1990.

24. Li XH, Deng SD, Fu H, et al. Synergism between rare earth cerium(IV) ion and vanillin on the corrosion of steel in $\mathrm{H}_{2} \mathrm{SO}_{4}$ solution: Weight loss, electrochemical, UV-vis, FTIR, XPS, and AFM approaches. Appl Surf Sci. 2008; 254:5574-5586. https://doi.org/10.1016/j.apsusc.2008.03.026 
25. Y1ld1z R, Dogan T, Dehri I. Evaluation of corrosion inhibition of mild steel in $0.1 \mathrm{M} \mathrm{HCl}$ by 4-amino-3-hydroxynaphthalene-1-sulphonic acid. Corros Sci. 2014;85:215-221. https://doi.org/10.1016/j.corsci.2014.04.017

26. Solmaz R. Investigation of corrosion inhibition mechanism and stability of Vitamin B1 on mild steel in 0.5 M HCl solution. Corros Sci. 2014;81:75-84. https://doi.org/10.1016/j.corsci.2013.12.006

27. Kertit $\mathrm{S}$, Hammouti B. Corrosion inhibition of iron in $1 \mathrm{M} \mathrm{HCl}$ by 1-phenyl-5mercapto-1,2,3,4-tetrazole. Appl Surf Sci. 1996;93:59-66. https://doi.org/10.1016/0169-4332(95)00189-1

28. Chevalier M, Robert F, Amusant N, et al. Enhanced corrosion resistance of mild steel in $1 \mathrm{M}$ hydrochloric acid solution by alkaloids extract from Aniba rosaeodora plant: Electrochemical, phytochemical and XPS studies. Electrochim Acta. 2014;131:96-105. https://doi.org/10.1016/j.electacta.2013.12.023

29. Roy P, Karfa P, Adhikari U, et al. Corrosion inhibition of mild steel in acidic medium by polyacrylamide grafted Guar gum with various grafting percentage: Effect of intramolecular synergism. Corros Sci. 2014;88:246-253. https://doi.org/10.1016/j.corsci.2014.07.039

30. Verma C, Singh P, Quraishi MA. A thermodynamical, electrochemical and surface investigation of Bis (indolyl) methanes as Green corrosion inhibitors for mild steel in $1 \mathrm{M}$ hydrochloric acid solution. J. Asso. Arab. Univ. Basic. Appl. Sci. 2015;21:24-30. https://doi.org/10.1016/j.jaubas.2015.04.003

31. Schultze JW, Wippermann K. Inhibition of electrode processes on copper by AHT in acid solutions. Electrochim Acta. 1987;32:823-831. https://doi.org/10.1016/0013-4686(87)85115-0

32. Bentiss F, Lebrini M, Lagrenee $M$, et al. The influence of some new 2,5disubstituted 1,3,4-thiadiazoles on the corrosion behaviour of mild steel in 1 $\mathrm{M} \mathrm{HCl}$ solution: AC impedance study and theoretical approach. Electrochim Acta. 2007;52:6865-6872. https://doi.org/10.1016/j.electacta.2007.04.111

33. Martinez S, Metikoš-Hukovic M. A nonlinear kinetic model introduced for the corrosion inhibitive properties of some organic inhibitors. J Appl Electrochem. 2003;33:1137-1142. https://doi.org/10.1023/B:JACH.0000003851.82985.5e

34. Lebrini M, Bentiss F, Chihib N, et al. Polyphosphate derivatives of guanidine and urea copolymer: Inhibiting corrosion effect of Armco iron in acid solution and antibacterial activity. Corros Sci. 2008;50:2914-2918. https://doi.org/10.1016/j.corsci.2008.07.003

35. Sibel ZOR, Dogan P, Yazici B. Inhibition of acidic corrosion of iron and aluminium by SDBS at different temperatures. Corros Rev. 2005;23:217-232. https://doi.org/10.1515/CORRREV.2005.23.2-3.217

36. Abdallah M. Rhodanine azosulpha drugs as corrosion inhibitors for corrosion of 304 stainless steel inhydrochloric acid solution. Corros Sci. 2002;44:717728. https://doi.org/10.1016/S0010-938X(01)00100-7

37. Morad MS, Kamal El-Dean AM. 2,20-Dithiobis(3-cyano-4,6dimethylpyridine): a new class of acid corrosion inhibitors for mild steel. Corros Sci. 2006;48:3398-3412. https://doi.org/10.1016/j.corsci.2005.12.006 
38. Gharebaa S, Omanovic S. Interaction of 12-aminododecanoic acid with a carbon steel surface. Towards the development of green corrosion inhibitors. Corros Sci. 2010;52:2104-2113. https://doi.org/10.1016/j.corsci.2010.02.019

39. Sethi T, Chaturvedi A, Updhyay RK, et al. Corrosion inhibitory effects of some schiffs bases on mild steel in acidic media. J Chil Chem Soc. 2007;52:1206-1213. http://dx.doi.org/10.4067/S071797072007000300003

40. Migahed MA, Mohammed HM, Al-Sabagh AM. Corrosion inhibition of H-11 type carbon steel in $1 \mathrm{M}$ hydrochloric acid solution by N-propyl amino lauryl amide and its ethoxylated derivatives. Mater Chem Phys. 2003;80:169-175. https://doi.org/10.1016/S0254-0584(02)00456-X

41. Solomon MM, Umoren SA, Udosoro II, et al. Inhibitive and Adsorption Behaviour of Carboxymethyl Cellulose on Mild Steel Corrosion in Sulphuric Acid Solution. Corros Sci. 2010;52:1317-1325. https://doi.org/10.1016/j.corsci.2009.11.041

42. Solomon MM, Umoren SA. Electrochemical and Gravimetric Measurements of Inhibition of Aluminium Corrosion by Poly (methacrylic acid) in $\mathrm{H}_{2} \mathrm{SO}_{4}$ Solution and Synergistic Effect of Iodide Ions. Measurement. 2015;76:104116. https://doi.org/10.1016/j.measurement.2015.08.029

43. El-Awady AA, Abd-El-Nabey BA, Aziz SG. Kinetic-thermodynamic and Adsorption Isotherms Analyses of the Inhibition of the Acid Corrosion of Steel by Cyclic and Open Chain Amines. J Electrochem Soc. 1992;139:21492154.

44. Abd El Rehim SS, Ibrahim AM, Khalid KF. The inhibition of 4-(20-amino-50methylphenylazo) Antipyrine on Corrosion of Mild Steel in $\mathrm{HCl}$ Solution. Mater Chem Phys. 2001;70:268-273. https://doi.org/10.1016/S02540584(00)00462-4

45. Ben Hmamou D, Salghi R, Zarrouk A, et al. Electrochemical and Gravimetric Evaluation of 7-methyl-2-phenylimidazo[1,2- $\alpha$ ]pyridine of Carbon Steel Corrosion in Phosphoric Acid Solution. Int J Electrochem Sci. 2013;8:1152611545.

46. Bilgic S, Sahin M. The corrosion inhibition of austenitic chromium-nickel steel in $\mathrm{H}_{2} \mathrm{SO}_{4}$ by 2-butyn-1-ol. Mater Chem Phys. 2001;70:290-295. https://doi.org/10.1016/S0254-0584(00)00534-4

47. Amin MA, Ahmed MA, Arida HA, et al. Monitoring corrosion and corrosion control of iron in $\mathrm{HCl}$ by non-ionic surfactants of the TRITON-X series-Part II. Temperature effect, activation energies and thermodynamics of adsorption. Corros Sci. 2011;53:540-548. https://doi.org/10.1016/j.corsci.2010.09.019

48. Bentiss F, Lebrini M, Lagrenee M. Thermodynamic characterization of metal dissolution and inhibitor adsorption processes in mild steel/2,5-bis(n-thienyl)1,3,4-thiadiazoles/hydrochloric acid system. Corros Sci. 2005;47:2915-2931. https://doi.org/10.1016/j.corsci.2005.05.034

49. Fouda AS, Al-Sarawy AA, El-Katori EE. Pyrazolone derivatives as corrosion inhibitors for C-steel in hydrochloric acid solution. Desalination. 2006;201:113. https://doi.org/10.1016/j.desal.2006.03.519 
50. Riggs OL, Hurd RM. Temperature Coefficient of Corrosion Inhibition. Corrosion. 1967;23:252-260. https://doi.org/10.5006/0010-9312-23.8.252

51. Szauer T, Brand A. Mechanism of inhibition of electrode reactions at high surface coverages-II. Electrochim Acta. 1981;26:1219-1224. https://doi.org/10.1016/0013-4686(81)85102-X

52. Solmaz R, Kardaş G, Culha M, et al. Investigation of adsorption and inhibitive effect of 2-mercaptothiazoline on corrosion of mild steel in hydrochloric acid media. Electrochim Acta. 2008;53:5941-5952. https://doi.org/10.1016/j.electacta.2008.03.055

53. Solmaz R, Kardaş G, Yazıcı B, et al. Adsorption and corrosion inhibitive properties of 2-amino-5-mercapto-1,3,4-thiadiazole on mild steel in hydrochloric acid media. Colloids Surf. A Physicochem Eng Aspects. 2008;312:7-17. https://doi.org/10.1016/j.colsurfa.2007.06.035

54. Gomma MK, Wahdan MH. Schiff bases as corrosion inhibitors for aluminium in hydrochloric acid solution. Mater Chem Phys. 1995;39:209-213. https://doi.org/10.1016/0254-0584(94)01436-K

55. Guan NM, Xueming L, Fei L. Synergistic inhibition between o-phenanthroline and chloride ion on cold rolled steel corrosion in phosphoric acid. Mater Chem Phys. 2004;86:59-68. https://doi.org/10.1016/j.matchemphys.2004.01.041

56. Obot IB, Macdonald DD, Gasem ZM. Density functional theory (DFT) as a powerful tool for designing new organic corrosion inhibitors. Part 1: An overview. Corros Sci. 2015;99:1-30. https://doi.org/10.1016/j.corsci.2015.01.037

57. Frisch MJ et al. Gaussian 09. Revision D. 01. (2009).

58. Lee C, Yang W, Parr RG. Development of the Colle-Salvetti correlationenergy formula into a functional of the electron density. Phys Rev B. 1988;37:785-789. https://doi.org/10.1103/PhysRevB.37.785

59. Pearson RG. Absolute electronegativity and hardness: application to inorganic chemistry. Inorg https://doi.org/10.1021/jo00267a034

60. Sastri V, Perumareddi J. Molecular orbital theoretical studies of some organic corrosion inhibitors.

Corrosion. 1997;53:617-622. https://doi.org/10.5006/1.3290294

61. Saha SK, Ghosh P, Hens A, et al. Density functional theory and molecular dynamics simulation study on corrosion inhibition performance of mild steel by mercapto-quinoline Schiff base corrosion inhibitor. Physica. E. 2015;66:332-341. https://doi.org/10.1016/j.physe.2014.10.035

62. Martinez S. Inhibitory mechanism of mimosa tannin using molecular modeling and substitutional adsorption isotherms. Mater Chem Phys. 2003;77:97-102. https://doi.org/10.1016/S0254-0584(01)00569-7

63. Cao Z, Tang Y, Cang H, et al. Novel benzimidazole derivatives as corrosion inhibitors of mild steel in the acidic media. Part II: Theoretical studies. Corros Sci. 2014; 83: 292-298. https://doi.org/10.1016/j.corsci.2014.02.025

64. Kokalj A. On the HSAB based estimate of charge transfer between adsorbates and metal surfaces. Chem https://doi.org/10.1016/j.chemphys.2011.10.021

Phys. 2012;393:1-12. 
65. Yüce AO, Telli E, Mert BD, et al. Experimental and quantum chemical studies on corrosion inhibition effect of 5,5 diphenyl 2-thiohydantoin on Mild Steel in $\mathrm{HCl}$ solution. $\quad \mathrm{J} \quad$ Mol $\quad$ Liq. 2016;218:384-392. https://doi.org/10.1016/j.molliq.2016.02.087

66. Kumar S, Sharma D, Yadav P, et al. Experimental and quantum chemical studies on corrosion inhibition effect of synthesized organic compounds on N80 steel in hydrochloric acid. Ind. Eng Chem Res. 2013;52:14019-14029. https://doi.org/10.1021/ie401308v

67. Benhiba F, Zarrok H, Elmidaoui A, et al. Theoretical prediction and experimental study of 2-phenyl-1, 4-dihydroquinoxaline as a novel corrosion inhibitor for carbon steel in 1.0 HCl. J. Mater Environ Sci. 2015;6(8):23012314.

68. Lebrini M, Lagrenee M, Traisnel M, et al. Enhanced corrosion resistance of mild steel in normal sulfuric acid medium by 2,5-bis(n-thienyl)-1,3,4thiadiazoles: Electrochemical, X-ray photoelectron spectroscopy and theoretical studies. Appl Surf Sci. 2007;253:9267-9276. https://doi.org/10.1016/j.apsusc.2007.05.062

69. Sikine M, Elmsellem H, Kandri Rodi Y, et al. Experimental, Monte Carlo simulation and quantum chemical analysis of1,5-di(prop-2-ynyl)benzodiazepine-2,4-dione as new corrosion inhibitor for mild steel in $1 \mathrm{M}$ hydrochloric acid solution. J Mater Environ Sci. 2017;8(1):116-133.

70. Abdel-Gaber AM, Abd-El-Nabey BA, Sidahmed IM, et al. Inhibitive action of some plant extracts on the corrosion of steel in acidic media. Corros Sci. 2006;48:2765-2779. https://doi.org/10.1016/j.corsci.2005.09.017

71. Lukovits I, Kálmán E, Zucchi F. Corrosion inhibitors - Correlation between electronic structure and efficiency. Corrosion. 2001;57:3-8.

72. Ahamad I, Prasad R, Quraishi M. Inhibition of mild steel corrosion in acid solution by Pheniramine drug: Experimental and theoretical study. Corros Sci. 2010;52:3033-3041. https://doi.org/10.1016/j.corsci.2010.05.022

73. Parr RG, Yang W. Density function approach to the frontier-electron theory of chemical reactivity. J Am Chem Soc. 1984;106:4049-4050. https://doi.org/10.1021/ja00326a036

74. Hu SQ, Hu JQ, Fan CC, et al. Theoretical and experimental study of corrosion inhibition performance of new imidazoline corrosion inhibitors. Acta Chim Sin. 2010;68:2051-2058.

75. Tan J, Guo L, Lv T, et al. Experimental and computational evaluation of 3indolebutyric acid as a corrosion inhibitor for mild steel in sulfuric acid. Int $\mathbf{J}$ Electrochem Sci. 2015;10:823-837.

76. Obot IB, Gasem ZM. Theoretical evaluation of corrosion inhibition performance of some pyrazine derivatives. Corros Sci. 2014;83:359-366. https://doi.org/10.1016/j.corsci.2014.03.008

77. Obot IB, Kaya S, Kaya C, et al. Density Functional Theory (DFT) modeling and Monte Carlo simulation assessment of inhibition performance of some carbohydrazide Schiff bases for steel corrosion. Physica E. 2016;80:82-90. https://doi.org/10.1016/j.physe.2016.01.024 
78. Kumar AM, Babu RS, Obot IB, et al. Fabrication of nitrogen doped graphene oxide coatings: experimental and theoretical approach for surface protection. RSC Adv. 2015;5:19264-19272. https://doi.org/10.1039/C4RA13470B

79. Verma C, Olasunkanmi LO, Obot IB, et al. 5-Arylpyrimido-[4,5-b]quinolinediones as new and sustainable corrosion inhibitors formild steel in $1 \mathrm{MHCl}$ : a combined experimental and theoretical approach. RSC Adv. 2016;6:1563915654. https://doi.org/10.1039/C5RA27417F

80. Obot IB, Kaya S, Kaya C, et al. Density Functional Theory (DFT) modeling and Monte Carlo simulation assessment of inhibition performance of some carbohydrazide Schiff bases for steel corrosion. Physica E Low-dimensional Syst Nanostructures. 2016;80:82-90. https://doi.org/10.1016/j.physe.2016.01.024

81. Kaya S, Banerjee P, Saha SK, et al. Theoretical evaluation of some benzotriazole and phospono derivatives asaluminum corrosion inhibitors: DFT and molecular dynamics simulation approaches. RSC Adv. 2016;6:7455074559. https://doi.org/10.1039/C6RA14548E 